\title{
Changes in Population Growth and Urban Space in Makkah City, Saudi Arabia
}

\author{
Ashraf Zakaria El-Abd*
}

\begin{abstract}
This study focused on changes in population growth and urban space in Makkah city. The research examined population size and growth based on the 1974, 1992, 2004 and 2010 census data. It concerned with studying the stages of urban growth in Makkah city, identify the directions of its horizontal growth and development through the addition of built-up area. The study's most important methodological approach was to blend data on population and urban growth from Makkah Al-Mukarramah's evolution over time, analyze the relationship between these aspects, and identify the extent of built-up area's capacity to absorb population increases. The results indicate the extent of the balance between supply (urban growth) and demand (population growth), as well as the evolution of urban density and per capita built-up area, which helps to identify population densification processes. The study's findings include future scenarios for this city with regard to population and built-up area, including estimates of the city's future population size and trends in urban growth. [Bul. Soc. Géog. d'Égypte, 2016, 89: 1-58]
\end{abstract}

Key Words: Population growth, urban space, Makkah Al-Mukarramah, Saudi Arabia.

\section{Introduction}

Geographers are more often concerned with local changes in population than with national change, and are interested in interpreting the complex patterns of population growth and decline (Clarke, 1972). Over time, a population grows and declines due to natural increase and net migration (United Nations, 2011). Growth and decline are essential topics in many national and sub-national population studies; they often serve as a starting point in identifying demographic trends and their implications for planning and policy making (Rowland, 2003). Challenges related to the spatial distribution of a population include rapid urbanization and population concentration, rural depopulation, urban management and slum dwelling (United Nations, 2013).

During the twentieth century, urbanization has been a major transforming force in most countries of the world (United Nations, 2010). Urbanization will be one of the most important demographic trends of the twenty-first century

* Department of Geography, Faculty of Arts, Helwan University, Egypt. 
(United Nations, 2001). Globally, more people live in urban areas than in rural areas. In 2007, for the first time in history, the global urban population exceeded the global rural population (United Nations, 2014). Almost all of this growth in urban population is expected to occur in developing countries (United Nations, 2013). Reducing or even reversing the flow of migrants from rural areas to cities has been the most common type of policy intervention pursued by Governments (United Nations, 2008).

The Kingdom of Saudi Arabia (KSA) has passed through three major stages over the course of the country's modern history. The first stage may be referred to as the unification of the kingdom, from 1902 to 1938. The second stage involves the discovery of oil and extends from 1939 to 1969 . The third stage involves a period of economic boom and planning that has spanned from 1970 to the present (Al-Seryane, 1991). During the 1970s and 1980s, employment opportunities grew due to infrastructure development project implementation in response to the economic boom that the KSA was experiencing (Al-Hajri, 2002). This process of increased employment opportunity primarily emerged after a rise in the country's income from oil revenues, which consequently increased spending on infrastructure projects and social development (Al-Thomaley, 1988). The population size of the KSA was 6,726,466 in 1974 and continued to rise until it reached $27,136,977$ in 2010.

One of the most important cities of the Makkah Al-Mukarramah region, Makkah city has the second largest population in the area and includes 60 districts. These districts show considerable variation in urban space and population size and growth. In the present study, each district was treated as a unit of analysis. Overall, migration has been an important influence on the population growth of Makkah city. The changes in population growth and urban space in Makkah appear to be mostly influenced by the environmental and geographical conditions that resulted in the increased migration that accompanied the oil boom, from both inside and outside of the KSA. Makkah's population size was $1,534,731$ in $2010-5.7 \%$ of the total population of the KSA.

Makkah is the location of the Holy Mosque and some holy sites (Mina, Muz-dalifa and Arafat), making it a destination for many migrants from inside and outside the KSA (Al-Jabri, 2008). The Holy Mosque is the central point of Makkah city, and the cultural, religious, spiritual and trade center and life of the city depend on its presence (Al-Saleh, 1991). The pilgrimage (Hajj) plays a major role in the revitalization of trade in the holy city, and pilgrimage is an important source of income in Makkah (Al-Seryane, 1986). The religious importance embodied in the presence of the Holy Mosque and holy sites is the major cause of the growth and prosperity for this city (AlGabbani, 1999). 


\section{Research Problem}

In terms of demography, Makkah city is currently facing high rates of population growth while still receiving large numbers of immigrants and inmigrants, resulting in a conflict between its urban space and population growth rate. This study examined past trends of population size and growth between 1974 and 2010 and factors that affect population growth, as well as the evolution of built-up area in approximately the same period. Projections were also made for the next 20 years to highlight the city's challenges.

\section{Study Relevance}

The topic under discussion is crucial since extremely few demographic studies have been carried out on Makkah city and none have focused on the conflict between the city's urban space and population growth rate. Therefore, the present study is not only important but also necessary because it seeks to address this research gap.

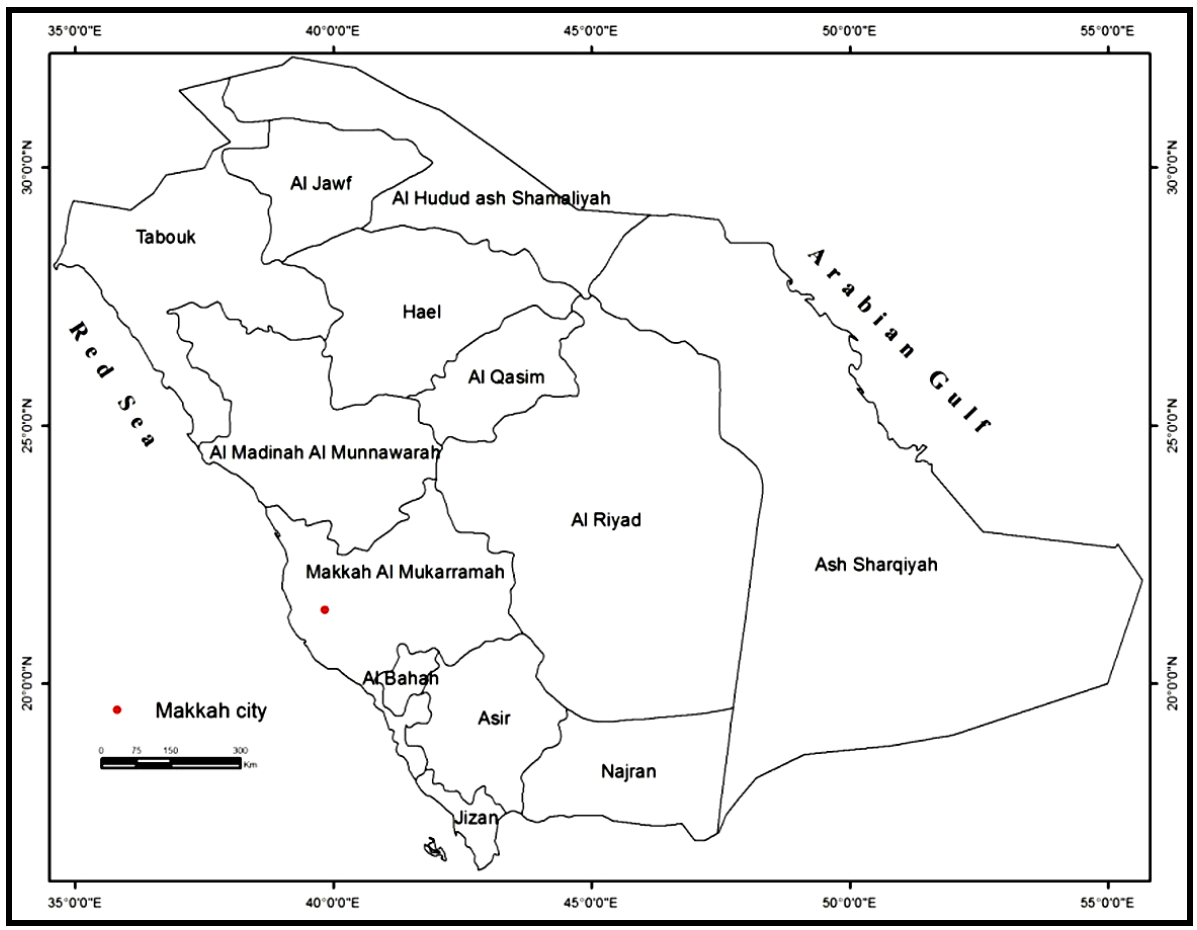

Figure 1. Administrative divisions of KSA and location of Makkah city.

Source: The central department of statistics \& information, ministry of economy and planning, KSA, 2010. 


\section{Study Objectives}

The main objectives of the study can be summarized as follows:

- To analyze the current levels and trends of population growth in Makkah city.

- $\quad$ To determine the factors responsible for these observed levels and trends of population growth.

- $\quad$ To predict the city's future population trends.

- $\quad$ To study the stages of urban growth in Makkah city.

- To identify the directions of its horizontal growth and developments in the addition of built-up area.

- $\quad$ To blend population and urban growth data on the historical development of Makkah and to analyze the relationship between these two aspects.

- To identify the extent of this urban cluster's capacity to absorb population increase.

\section{Literature Review}

Al-Seryane (1986) studied population change in Makkah city from 1974 to 1983 . His research revealed that the city had already experienced significant changes in demographic, economic, and population distribution. Al-Jabri (2008), in turn, studied the geography of settlement centers in the administrative region of makkah Al-Mukarramah.

\section{Study Hypothesis}

The main hypotheses are as follows:

- Immigration has an important role in population growth.

- The religious function of Makkah city has a significant impact on its attractiveness to international migrants.

- Population growth in Makkah is related to the city's level of development.

- A conflict exists between the city's population and urban growth that will continue into the future.

\section{Geographical Location of The Study Area}

Makkah city is located in the southwest part of the KSA, about 80 kilometers $(\mathrm{km})$ east of the Red Sea. The city extends between the longitudes of $39^{\circ} 35^{\prime}$ and $40^{\circ} 02^{\prime}$ east and latitudes of $21^{\circ} 09^{\prime}$ and $21^{\circ} 37^{\prime}$ north, as shown in Figures (1) and (2).

\section{Methodology}

This study used statistics and data tabulation of population growth rates. A projection technique was implemented to estimate future population size for different scenarios of population growth rate over a period of 20 years, as discussed in more detail in section four below. 


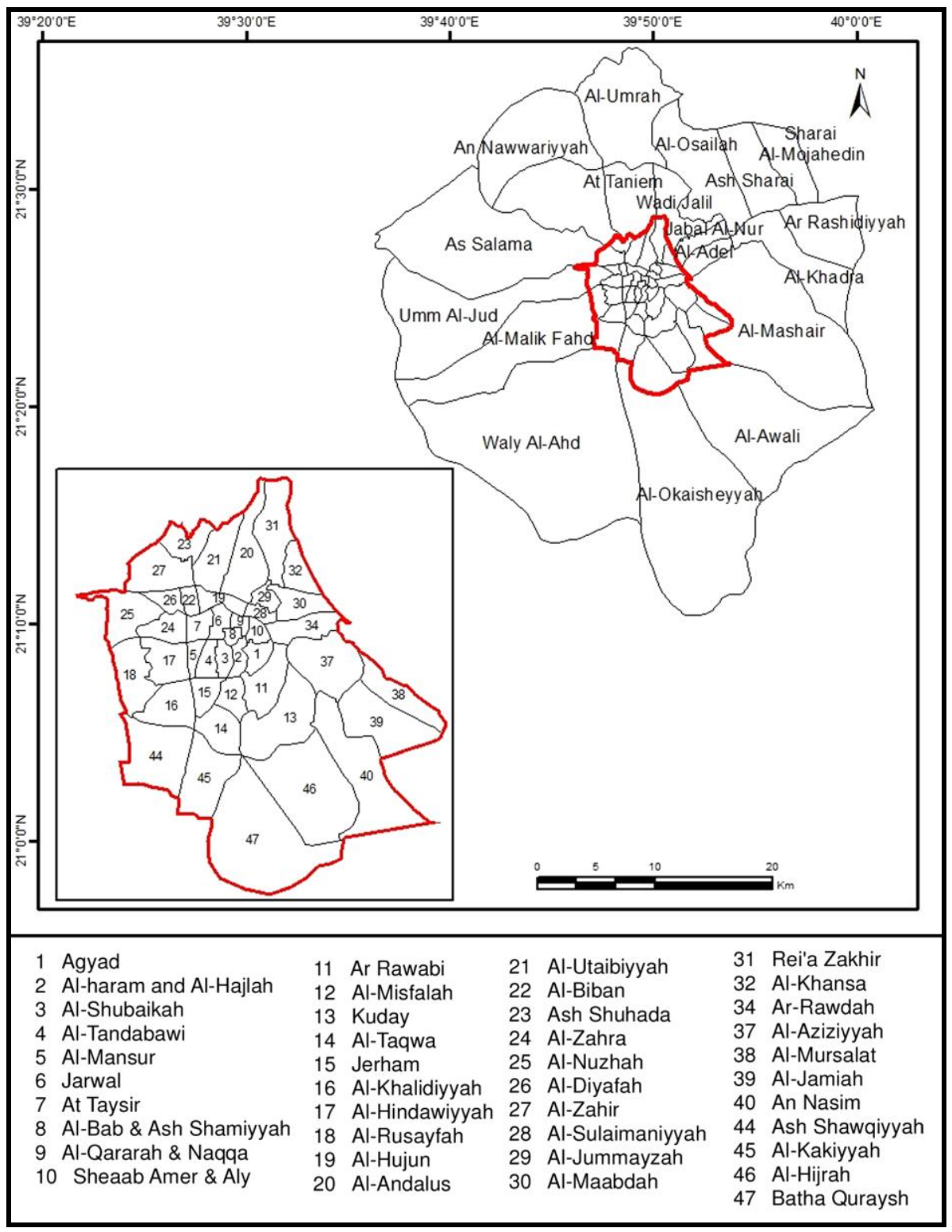

Figure 2. Administrative districts of Makkah city in 2010.

Source: Makkah region development authority, 2010. 
The following exponential equation (Siegel and Swanson, 2004) was used to compute population growth rates and projections:

$$
\begin{aligned}
& r=1 / n \ln P n / P 0 \\
& P n=P O e^{r n}
\end{aligned}
$$

In which $r$ is the exponential rate of growth, $n$ is the length of the interval in years, $l n$ is the natural logarithm, $P n$ is the population at the end of the interval, $P O$ is the initial population, and $e$ is the base of natural logarithms.

The software used in this research was mainly the GIS software package ESRI ArcGIS. This included the ArcMap/ArcCatalog package, of which version 10.1 was used.

\section{Data Sources}

The data used in this research fall into the two categories described in the subsections below.

\section{- Population Data}

The KSA does not have a long history of census taking. The census of 1974 was the first of its kind, and, since then, the practice of census taking has continued more or less once every 10 years. By 2010, the KSA had completed four successive censuses.

The KSA's central department of statistics and information was the ultimate source of the population data used in this study. The data were obtained primarily from four censuses conducted from 1974 to 2010.

\section{- Remote Sensing Data}

The remote sensing data used in this study were obtained from Landsat images. These images were acquired in 1972, 1990, 2000, 2007, and 2013.

\section{Study Organization}

This study is organized into four sections following the above introductory statements and followed by conclusions and recommendations based on the findings. Section one deals with changes in population size and growth. The second section discusses the evolution of the built-up area under study. The third section blends population and urban growth data and analyzes the relationship between these aspects. The last section presents projections of future population growth and built-up area. 


\section{Study Limitations}

The study's results are limited by the absence of data, in particular, on vital statistics. The study used data that only cover the period from the 1970 s to late 2013.

\section{Changes in Population Size and Growth}

\section{Changes in Population Size}

This section's main goal is to examine Makkah's population size and growth based on the 1974, 1992, 2004 and 2010 census data. The city's population size increased from 366,509 in 1974 , to $1,534,731$ in 2010 , for a total increase of $1,168,222$ over the entire 36 years. This means that the population size increased approximately 4.2 -fold during this period (Table 1). The rise was due to internal migration from rural and Bedouin areas to the city, as well as international migrants who came to work in the city. By 2010 , $46.52 \%$ of the city's population was non-Saudi.

Table 1. The absolute evolution of Makkah's population (1974-2010).

\begin{tabular}{|c|c|c|c|c|c|}
\hline \multirow{2}{*}{$\begin{array}{c}\text { Census } \\
\text { year }\end{array}$} & \multirow{2}{*}{ No. of population } & \multicolumn{2}{c|}{$\begin{array}{c}\text { Size of } \\
\text { population increase }\end{array}$} & \multicolumn{2}{c|}{$\begin{array}{c}\text { Ratio of } \\
\text { population increase }\end{array}$} \\
\cline { 3 - 6 } & & Total & Annual & Total & Annual \\
\hline 1974 & 366,509 & - & - & - & - \\
\hline 1992 & 965,697 & 599,188 & 32,224 & 163.5 & 8.8 \\
\hline 2004 & $1,294,168$ & 328,471 & 26,633 & 34 & 2.8 \\
\hline 2010 & $1,534,731$ & 240,563 & 41,596 & 18.6 & 3.2 \\
\hline
\end{tabular}

Source: Calculated by the author from Makkah's population censuses (1974-2010), central department of Statistics and information, KSA.

Some important reasons for this increase include, first, the oil boom in the KSA that resulted in a social, urban, and economic renaissance and, second, the concentration of overall development in Makkah city. The largest proportion of the total increase $(163.5 \%)$ occurred during the first census period, so the population size increased approximately 2.6-fold during this period.

Table (2) presents the geographical distribution of population and changes in size over time of the 22 cities of the surrounding region that maintained the highest populations from 1974 to 2010. It shows an unequal distribution of population across the cities, and only two cities (Jiddah and Makkah) contained more than half of the total population of these cities, in 2010. This dominance is due to the concentration of most regional development in these cities. 
The data on the population numbers and percentage distribution in these cities show that Jiddah has dominated with more than half of the total population of these cities. Its population increased from 2,801,481 in 2004$55.3 \%$ of the total population of these cities in that year-to $3,430,697$ in $2010-56.4 \%$ of the total population of these cities in that year. This is a total increase of 629,216 and an approximately 1.2-fold increase of this city's population size during the specified period. The steady rise in Jiddah's population can be attributed to economic prosperity resulting from development programs, which increased the availability of job opportunities and attracted large numbers of migrants from inside and outside the KSA.

Table 2. The evolution of the absolute and percentage distribution of population size among the major cities of the Makkah Al-Mukarramah Region (2004-010).

\begin{tabular}{|l|c|c|c|c|}
\hline \multirow{2}{*}{ City } & \multicolumn{2}{c|}{$\mathbf{2 0 0 4}$} & \multicolumn{2}{c|}{$\mathbf{2 0 1 0}$} \\
\cline { 2 - 5 } & No. & \% & No. & \% \\
\hline Jiddah & $2,801,481$ & 55.3 & $3,430,697$ & 56.4 \\
\hline Makkah Al-Mukarramah & $1,294,168$ & 25.5 & $1,534,731$ & 25.2 \\
\hline At-Taif & 521,273 & 10.3 & 579,970 & 9.5 \\
\hline Al-Huwaya & 132,078 & 2.6 & 148,151 & 2.4 \\
\hline Bahrah & 59,809 & 1.2 & 75,213 & 1.2 \\
\hline Rabigh & 40,986 & 0.8 & 55,304 & 0.9 \\
\hline Al-Khurmah & 24,026 & 0.5 & 27,032 & 0.4 \\
\hline Turubah & 22,836 & 0.5 & 25,937 & 0.4 \\
\hline Al-Jumum & 21,825 & 0.4 & 25,601 & 0.4 \\
\hline Al-Qunfidhah & 20,317 & 0.4 & 24,512 & 0.4 \\
\hline Al-Qouz & 20,248 & 0.4 & 23,391 & 0.4 \\
\hline Ranyah & 19,643 & 0.4 & 21,656 & 0.4 \\
\hline Khulays & 16,879 & 0.3 & 19,331 & 0.3 \\
\hline Al-Lith & 15,591 & 0.3 & 18,430 & 0.3 \\
\hline Thuwal & 8,075 & 0.2 & 17,792 & 0.3 \\
\hline Adham & 9,063 & 0.2 & 10,484 & 0.2 \\
\hline Ashayrah & 7,276 & 0.1 & 8,425 & 0.1 \\
\hline Al-Muwayh & 7,237 & 0.1 & 8,553 & 0.1 \\
\hline Al-Muzaylif & 7,083 & 0.1 & 8,508 & 0.1 \\
\hline Al-Hada & 6,767 & 0.1 & 8,819 & 0.1 \\
\hline Mastorah & 6,489 & 0.1 & 7,034 & 0.1 \\
\hline Dhahban & 5,260 & 0.1 & 7,161 & 0.1 \\
\hline & $\mathbf{5 , 0 6 8 , 4 1 0}$ & $\mathbf{1 0 0 . 0}$ & $\mathbf{6 , 0 8 6 , 7 3 2}$ & $\mathbf{1 0 0 . 0}$ \\
\hline Sour & 0.49 \\
\hline
\end{tabular}

Source: Calculated by the author from the Makkah Al-Mukarramah Region's population censuses (2004-2010). 
Makkah came in second place with an increase in population size from $1,294,168$ in $2004-25.5 \%$ of the total population of these cities in that year-to $1,534,731$ in $2010-25.2 \%$ of the total population of these cities in the same year-for a total increase of 240,563. These changes in Makkah appear to be mostly influenced by environmental and geographical conditions that accompanied the oil boom, resulting in increased migration from both inside and outside of the KSA. In addition to internal and international migration, the developmental activities primarily concentrated in Makkah may have also caused the population distribution to shift in favor of this city.

At-Taif came in third place, with its portion of the population increasing from $10.3 \%$ of the 22 cities' total population, in 2004 , to $9.5 \%$, in 2010 . Sixteen of the cities maintained their places in the top sixteen highest populations from 2004 to 2010 . Ashayrah, after it was ranked seventeenth in 2004, fell to twentieth, in 2010. Al-Muwayh and Al-Muzaylif maintained their rank of eighteenth and nineteenth, respectively, from 2004 to 2010. AlHada, after it was ranked twentieth, in 2004, rose to seventeenth, in 2010. Mastorah was ranked twenty-first but fell to twenty-second, in 2010, and Dhahban's rank of twenty-second, in 2004, changed to twenty-first, in 2010.

\section{Geographical Distribution of the Population (2004-2010)}

Table (3) shows that Makkah included 60 districts in 2010, including eight districts ranking at the top, in 2010. Al-Hindawiyyah comes first with $5.3 \%$ of the city's population, followed by the districts of Al-Jamiah, AlZahra, Al-Taqwa, Al-Khalidiyyah, Al-Tandabawi, Ar Rashidiyyah, and AlAndalus with the ratios, respectively, of $4.2 \%, 3.8 \%, 3.7 \%, 3.6 \%, 3.5 \%$, $3.2 \%$, and $3.1 \%$. The rest of the districts each contain less than $3 \%$ of the city's total population for the same year.

Makkah's districts can be divided into five groups according to the geographical distribution of population from 2004 to 2010, as follow:

- Group 1: These districts' population includes more than 70,000 people. The city included, in 2004, only one such district: Al-Hindawiyyah. its population was 70,564, and this continued until 2010, when its population grew to 81,742 . This was equivalent to $5.3 \%$ of the city's total population in that year and was due to this district receiving more immigrants, especially from Africa.

- Group 2: These districts' population ranges from 50,000 to 70,000. The city experienced a steady increase in the number of these districts, as, in 2004, the city included only one such district-Al-Jamiah, with a population size of 54,076 which is equivalent to $4.2 \%$ of the total population of the city in that year. The number of districts in this group then grew to five, in 2010 , including $18.8 \%$ of the city's total population. 


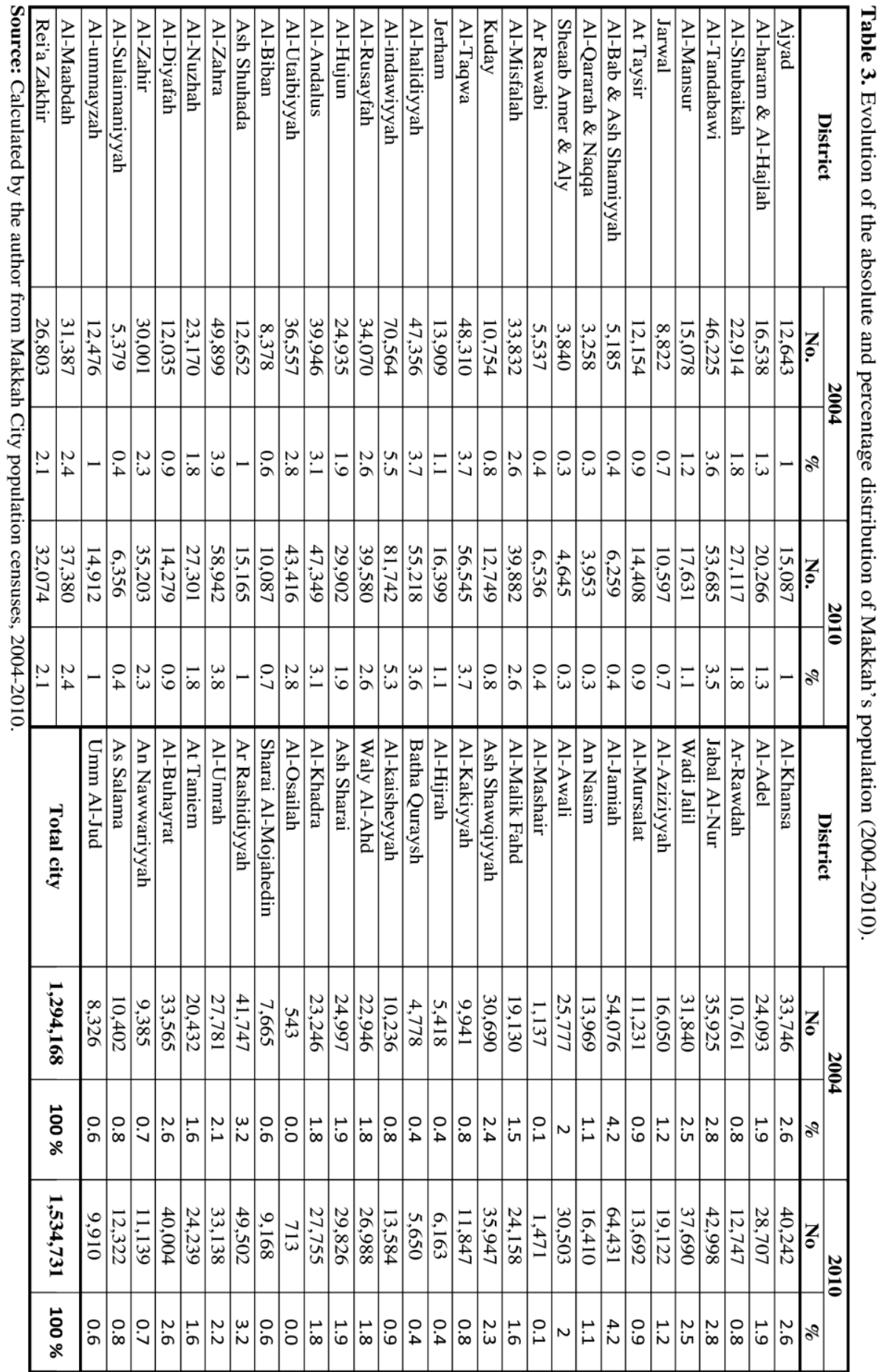


This trend was due to increases in the population, from 2004 to 2010, and the growth of some districts, such as Al-Tandabawi, Al-Taqwa, AlKhalidiyyah, Al-Zahra, and Al-Jamiah, which put them in a higher category of population size during that period. This was due to immigration into these districts of people with limited income.

- Group 3: These districts' population ranges from 30,000 to 50,000. This group shrunk from 16 district, in 2004, with $46.8 \%$ of the city's total population in that year, to 15 districts, in 2010 , with $38.1 \%$ of the city's total population in that year. This trend was due to an increase in the population size from 2004 to 2010 and the movement of some districts, such as Al-Tandabawi, Al-Taqwa, Al-Khalidiyyah, and Al-Zahra, to a higher category of population size during that period.

- Group 4: These districts' population ranges from 10,000 to 30,000. This group included 27 districts, in $2004-37 \%$ of the city's total population in that year-and increased to 28 , in $2010-33.8 \%$ of the city's total population in that year. This was due to an increase in the overall population from 2004 to 2010, moving some districts, such as Rei'a Zakhir, Al-Awali, and Al-Umrah, into a higher category of population size during that period. This trend was the result of the growing prosperity of urbanized settlements along roads and intra-city migration from older to planned districts in the city.

- Group 5: These districts' population is less than 10,000. This group included 15 districts, in 2004, including $6.7 \%$ of the city's total population in that year. The number dropped to 11 districts in 2010 , to $3.9 \%$ of the city's total population in that year. This trend was due to an increase in the population size from 2004 to 2010, as a result of which, some districts, such as Jarwal, Al-Biban, Al-Kakiyyah, and An Nawwariyyah, moved into a higher category of population size during that period (Figure 3).

The data on the proportional increase in districts' population size in Makkah, from 2004 to 2010, show that 30 districts have experienced proportional increases greater than the city's general increase of $18.6 \%$, including four districts that occupied the top four ranks during that period. Al-Okaisheyyah experienced the largest relative increase (32.7\%), followed by Al-Osailah, Al-Mashair, and AlMalik Fahd with increase ratios, respectively, of $31.3 \%, 29.4 \%$, and $26.3 \%$. These changes were due to increased intra-city migration and developmental activities concentrated primarily in these planned districts.

The districts of Kuday, Al-Diyafah, Ar Rashidiyyah, and At Taniem achieved proportional increases equal to the city's general increase. While the remaining districts recorded proportional increases less than the city's overall ratio, their ratios ranged from $13.8 \%$ in Al-Hijrah to $18.5 \%$ in At Taysir, AlAndalus, Ar-Rawdah, and As Salama (Table 4). 


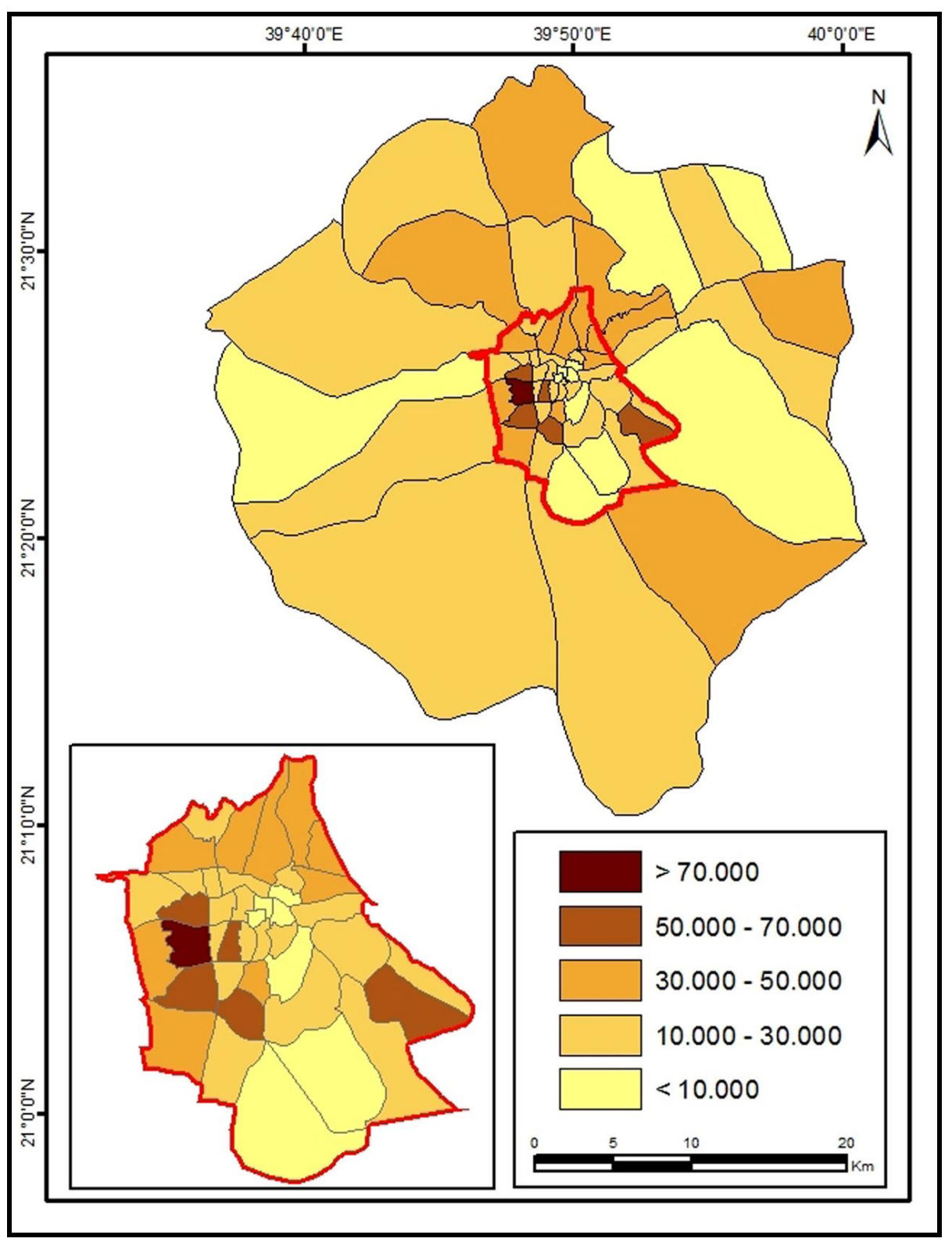

Figure 3. Geographical distribution of the population in Makkah's districts: 2010. 


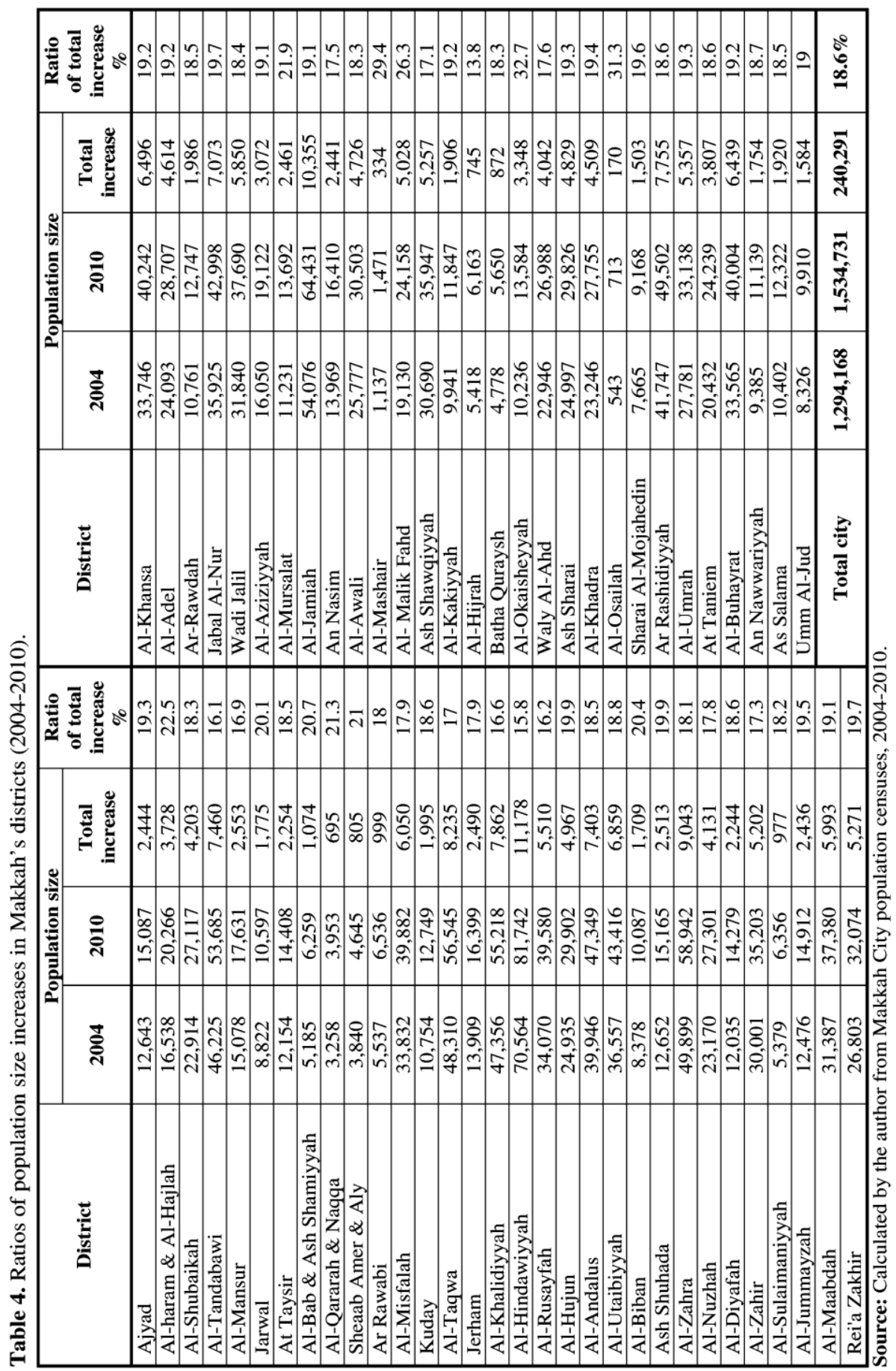




\section{Changes in Population Growth}

The data on population growth rates in Makkah show that, during the first census period (1974-1992), the city recorded its highest population growth rate $(5.35 \%)$, which then decreased to $2.40 \%$ in the second census period (1992-2004). The rate then increased again to $2.99 \%$ during the last census period (2004-2010). The main reason for this high population growth rate is the concentration of development projects in the city, which has led to increased job opportunities and consequently increased immigration and migration streams from rural areas.

Population growth rates of the KSA have declined between 1974 and 2010, during which time the rate declined from 5\% from 1974 to 1992 to $2.4 \%$ from 1992 to 2004 and then rose to $3.1 \%$ during the last census period from 2004 to 2010 . The major reason for this decline in the population growth rate is attributable the Kingdom's adoption of a policy that replaced international labor with Saudi employees. Nonetheless, the trend still exhibits a relatively high rate of growth (Table 5).

Table 5. Population growth rate in Makkah city and KSA (1974-2010).

\begin{tabular}{|c|c|c|}
\hline \multirow{2}{*}{ Census period } & \multicolumn{2}{|c|}{ Growth rate (\%) } \\
\cline { 2 - 3 } & Makkah city & KSA \\
\hline $1974-1992$ & 5.35 & 5 \\
\hline $1992-2004$ & 2.40 & 2.4 \\
\hline $2004-2010$ & 2.99 & 3.1 \\
\hline
\end{tabular}

Source: Calculated by the author from population censuses, 1974-2010.

\section{Geographical Distribution of The Population Growth (2004-2010)}

The data on population growth rates in Makkah's districts show that, during the census period of 2004 to 2010, 34 districts recorded rates higher than the city's general growth rate of $2.94 \%$ during the same period. These included four districts that occupied the top four ranks during that period: Al-Okaisheyyah with the largest population growth (4.89\%), followed by Al-Osailah, Al-Mashair, and Al-Malik Fahd with the respective rates of $4.71 \%, 4.45 \%$, and $4.04 \%$ This was due to increased intra-city migration from older districts and developmental activities concentrated primarily in planned districts.

The districts of At Taysir, Kuday, and Al-Andalus experienced a population growth equal to the city's overall growth rate, while the remaining districts recorded a population growth of less than the overall rate. These rates ranged from 2.23\%, in Al-Hijrah, to 2.93\%, in Ar-Rawdah and As Salama (Table 6 and Figure 4). 
Table 6. Differential population growth rates in Makkah's districts (2004-2010).

\begin{tabular}{|c|c|c|c|}
\hline District & $\begin{array}{c}\text { Growth } \\
\text { rate }(\%) \\
2004-2010\end{array}$ & District & $\begin{array}{c}\text { Growth } \\
\text { rate }(\%) \\
2004-2010\end{array}$ \\
\hline Ajyad & 3.06 & Al-Khansa & 3.04 \\
\hline Al-haram \& Al-Hajlah & 3.51 & Al-Adel & 3.03 \\
\hline Al-Shubaikah & 2.91 & Ar-Rawdah & 2.93 \\
\hline Al-Tandabawi & 2.59 & Jabal Al-Nur & 3.11 \\
\hline Al-Mansur & 2.70 & Wadi Jalil & 2.92 \\
\hline Jarwal & 3.17 & Al-Aziziyyah & 3.03 \\
\hline At Taysir & 2.94 & Al-Mursalat & 3.43 \\
\hline Al-Bab \& Ash Shamiyyah & 3.26 & Al-Jamiah & 3.03 \\
\hline Al-Qararah \& Naqqa & 3.34 & An Nasim & 2.78 \\
\hline Sheaab Amer \& Aly & 3.29 & Al-Awali & 2.91 \\
\hline Ar Rawabi & 2.87 & Al-Mashair & 4.45 \\
\hline Al-Misfalah & 2.84 & Al-Malik Fahd & 4.04 \\
\hline Kuday & 2.94 & Ash Shawqiyyah & 2.73 \\
\hline Al-Taqwa & 2.72 & Al-Kakiyyah & 3.03 \\
\hline Jerham & 2.85 & Al-Hijrah & 2.23 \\
\hline Al-Khalidiyyah & 2.66 & Batha Quraysh & 2.90 \\
\hline Al-Hindawiyyah & 2.54 & Al-Okaisheyyah & 4.89 \\
\hline Al-Rusayfah & 2.59 & Waly Al-Ahd & 2.81 \\
\hline Al-Hujun & 3.14 & Ash Sharai & 3.05 \\
\hline Al-Andalus & 2.94 & Al-Khadra & 3.07 \\
\hline Al-Utaibiyyah & 2.97 & Al-Osailah & 4.71 \\
\hline Al-Biban & 3.21 & Sharai Al-Mojahedin & 3.10 \\
\hline Ash Shuhada & 3.13 & Ar Rashidiyyah & 2.95 \\
\hline Al-Zahra & 2.88 & Al-Umrah & 3.05 \\
\hline Al-Nuzhah & 2.84 & At Taniem & 2.95 \\
\hline Al-Diyafah & 2.96 & Al-Buhayrat & 3.03 \\
\hline Al-Zahir & 2.76 & An Nawwariyyah & 2.96 \\
\hline Al-Sulaimaniyyah & 2.89 & As Salama & 2.93 \\
\hline Al-Jummayzah & 3.08 & Umm Al-Jud & 3.01 \\
\hline Al-Maabdah & 3.02 & \multirow{2}{*}{ Total city } & \multirow{2}{*}{2.94} \\
\hline Rei'a Zakhir & 3.10 & & \\
\hline
\end{tabular}

Source: Calculated by the author from Makkah city population censuses, 2004-2010.

A study of the number of years required for the population of Makkah's districts to double in size showed that 33 districts needed less time than the number of years required for the city's overall population to double (23.8 years). These included three districts occupying the top three ranks, among which Al-Okaisheyyah recorded the lowest number of years (14.3), followed by Al-Osailah, and Al-Mashair with 14.9 and 15.7 years, respectively. 


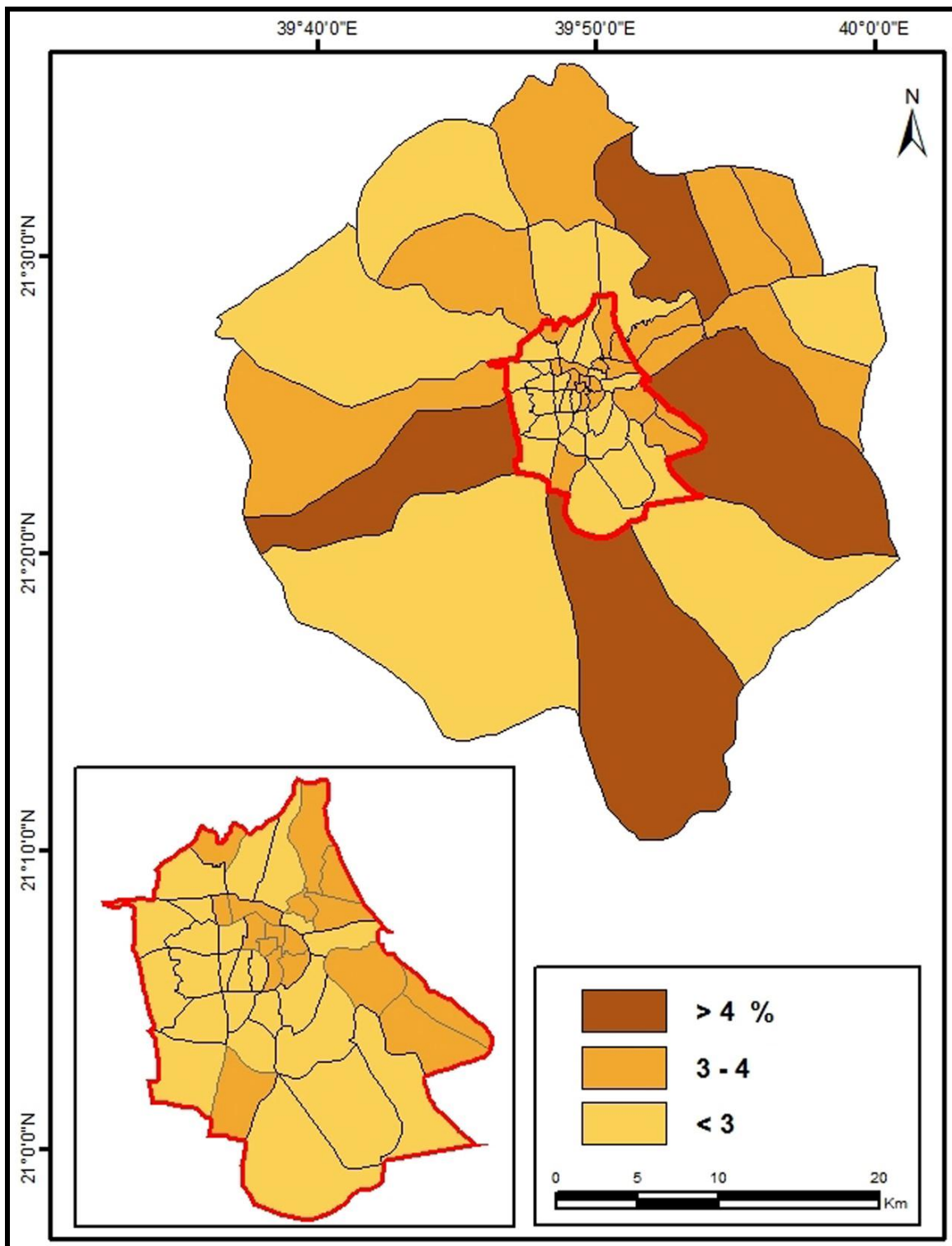

Figure 4. Population growth rates in Makkah's districts: 2004-2010.

The districts of At Taysir, Kuday, Al-Andalus, and Ar Rashidiyyah matched the overall city's growth in the same number of years as the city as a whole. The remaining districts recorded a number of years greater than the city's overall number of years, ranging from 31.4 years, in Al-Hijrah, to 23.9 years, in Ar-Rawdah and As Salama (Table 7). 


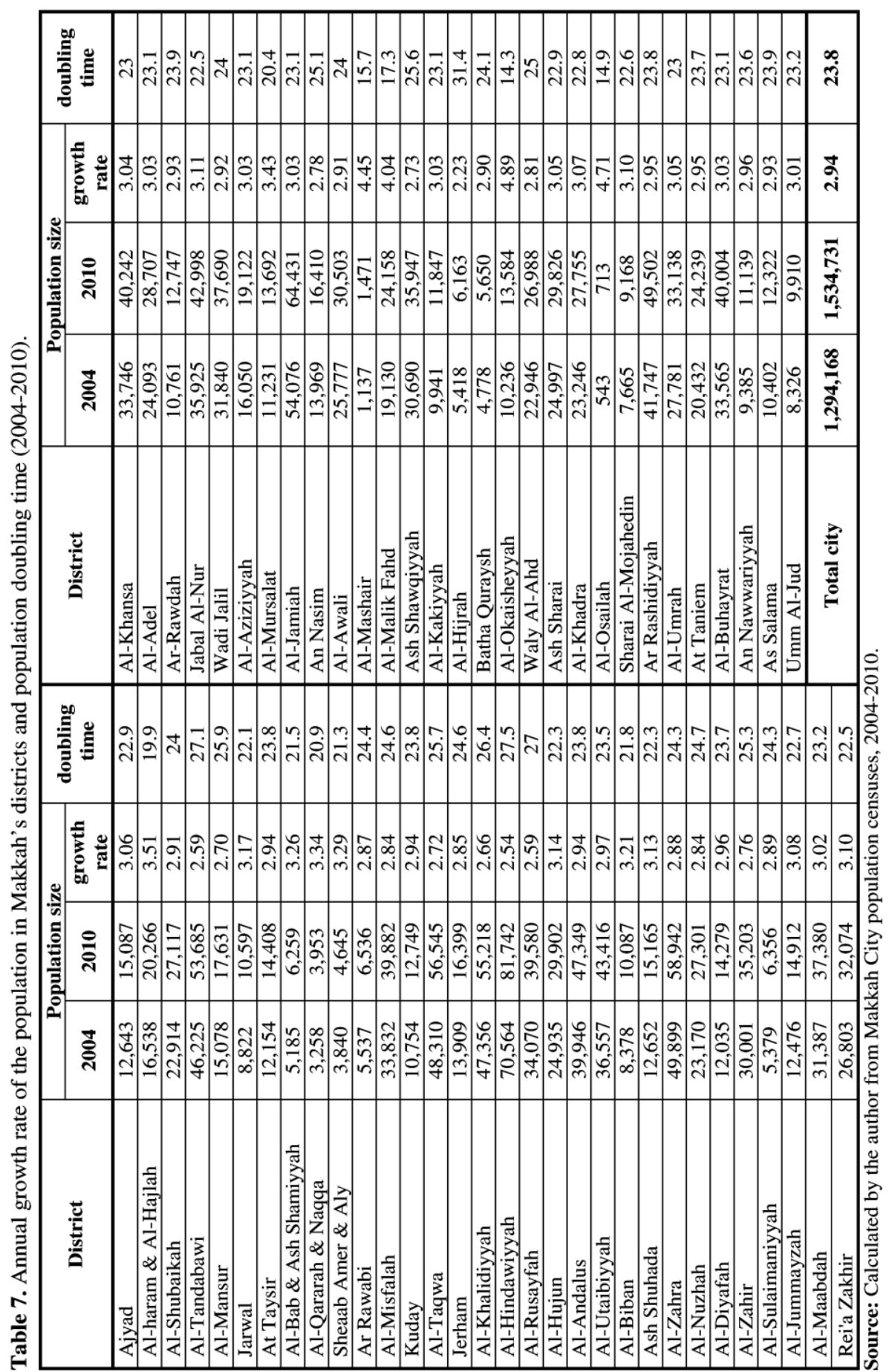




\section{Evolution of Built-up Area}

This section focuses on the stages of urban growth in Makkah city. This includes identifying horizontal urban growth directions and the development of added built-up areas.

\section{Stages of Urban Growth}

An analysis of the data shown in Appendix (1) and the compound map of horizontal urban growth of Makkah (Figures 5-10) clearly shows that the city has passed through four stages of urban growth from its inception until the present. The following subsections highlight the spread of urban sprawl in each stage.

\section{- Early Stage before 1972}

Urban sprawl during this stage reached out more than five kms from the core (the Holy Mosque) to the east-southeast (ESE) and south-southwest (SSW). In the ESE, the growth was contained in the Ajyad and Al-Jamiah districts. To the SSW, the sprawl appeared in the Al-Misfalah, Al-Taqwa and Al-Kakiyyah districts.

Urban sprawl ranged from three to five kms from the core to the northnortheast (NNE), northeast (NE), east-northeast (ENE), east (E), westnorthwest (WNW), northwest (NW), and north-northwest (NNW). In the NNE, the sprawl reached into the districts of Sheaab Amer \& Aly, AlSulaimaniyyah, Al-Jummayzah, and Rei'a Zakhir. To the NE, the growth spread in the Sheaab Amer \& Aly, Al-Sulaimaniyyah, Al-Maabdah, and Jabal Al-Nur districts. In the ENE, the sprawl appeared in the Sheaab Amer \& Aly, Al-Maabdah, and Al-Adel districts. To the E, the growth extended into both Ajyad and Al-Aziziyyah. In the WNW, the sprawl reached the Al-Bab \& Ash Shamiyyah, Jarwal, At Taysir, Al-Zahra, and Al-Nuzhah districts. To the NW, the growth was in the districts of Al-Bab \& Ash Shamiyyah, Jarwal, At Taysir, Al-Hujun, Al-Biban, and Al-Zahir. In the NNW, the sprawl was detectable in the Al-Bab \& Ash Shamiyyah, Jarwal, Al-Qararah \& Naqqa, Al-Hujun, and Al-Utaibiyyah districts.

Urban sprawl ranged from one to three $\mathrm{kms}$ from the core to the north $(\mathrm{N})$, southwest (SW), west-southwest (WSW), and west (W). To the N, the growth appeared in the districts of Al-Qararah \& Naqqa, Al-Hujun, and AlAndalus. In the SW, the sprawl reached into the Al-Shubaikah and Jerham districts. To the WSW, the growth was found in the Al-Shubaikah, AlTandabawi, Al-Mansur, and Al-Hindawiyyah districts. In the W, the sprawl was in the districts of Al-Shubaikah, Al-Tandabawi, Al-Mansur, and AlHindawiyyah. 
Urban sprawl reached less than one $\mathrm{km}$ from the core to the southeast (SE), south-southeast (SSE), and south (S). To the SE, the growth appeared in the Ajyad district. In the SSE, the sprawl also reached into the Ajyad district. To the S, the growth was only in the Al-haram \& Al-Hajlah district. As can be observed from the above, the urban growth of the city during this stage took a circular form around the Holy Mosque (Figure 5).

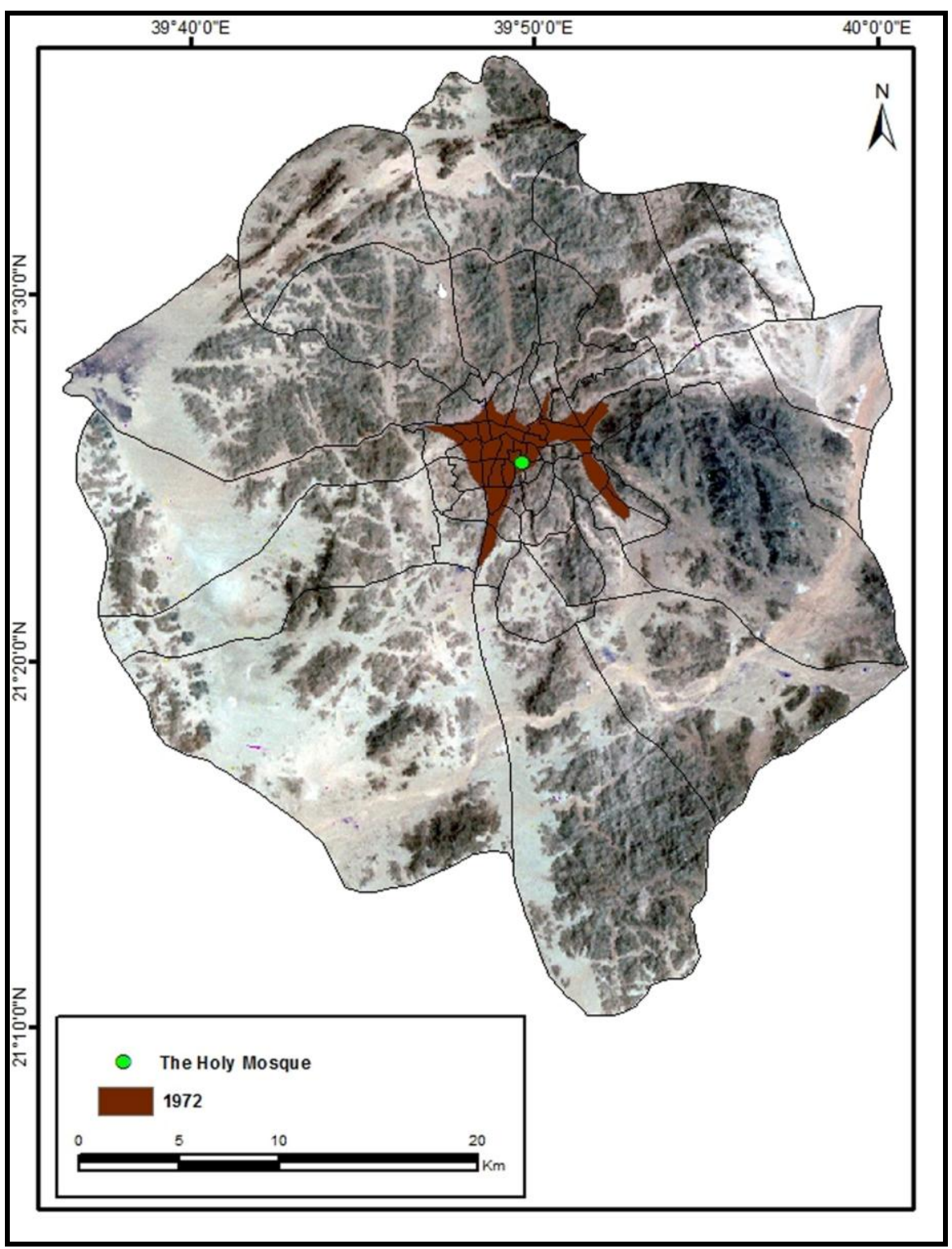

Figure 5. Built-up area of Makkah city: until 1972. 


\section{- First Urban Boom Stage (1972-1990)}

The incremental growth in the city's urban sprawl during this stage reached more than $10 \mathrm{kms}$ in three directions: ENE, SE, and NNW. In the ENE, the sprawl extended into the districts of Al-Khadra and Ar Rashidiyyah and filled in spaces in the Al-Adel district. To the SE, the growth appeared in the An Nasim and Al-Awali districts. In the NNW, the sprawl was in the Ash Shuhada, At Taniem, Al-Buhayrat, and An Nawwariyyah districts. In these three directions, the urban sprawl was associated with growth in the ENE along the Al-Sail road; in the SE, with the Al-Taif road; and, in the NNW, with the Al-Madina Al- Monawara road.

The urban sprawl's growth also ranged from five to $10 \mathrm{kms}$ to the ESE and S. To the ESE, the sprawl extended into the districts of Al-Aziziyyah and Al-Mursalat, as well as filling spaces in Al-Jamiah. The urban growth in this direction was associated with the Al-Taif road. In the S, the sprawl went into the Kuday and Batha Quraysh districts.

The incremental growth in urban sprawl ranged from one to five kms to the N, NE, E, SSE, SSW, SW, WSW, and W. In the N, the sprawl was in the At Taniem district and filled in spaces in the Al-Andalus district. To the NE, the sprawl appeared in the district of Al-Khansa, filling in spaces in the Al-Maabdah and Jabal Al-Nur districts. In the E, the growth filled spaces left in the AlAziziyyah district, and the urban growth in this direction was stopped by the boundaries of the holy sites. To the SSE, the sprawl entered the districts of Ar Rawabi, Kuday, and Al-Hijrah. In the SSW, the sprawl extended into the Waly Al-Ahd district, as well as filling in spaces in the Al-Kakiyyah district. The urban growth in this direction was associated with the Al-Laith road. To the SW, the sprawl was in the Al-Khalidiyyah and Ash Shawqiyyah districts, and the urban growth in this direction was also associated with the Al-Laith road. In the WSW, the sprawl ran into the Al-Rusayfah and Al-Malik Fahd districts. To the W, the sprawl extended into the districts of Al-Rusayfah and Umm Al-Jud, while this urban growth was associated with the Jiddah road.

The growth of urban sprawl reached less than one $\mathrm{km}$ to the NNE, WNW, and NW. In the NNE, spaces were filled in the Rei'a Zakhir district. To the WNW, the sprawl was in the As Salama district and filled spaces in the districts of Al-Nuzhah and Al-Zahra. In the NW, the sprawl extended into the Al-Buhayrat district, filling spaces left in the Al-Zahir district (Figure 6).

\section{- Retreat Stage (1990-2007)}

The incremental growth in urban sprawl during this third stage reached more than two kms in one direction (NNE), and the sprawl appeared in the Wadi Jalil district. The sprawl also filled spaces in the district of Rei'a Zakhir. 


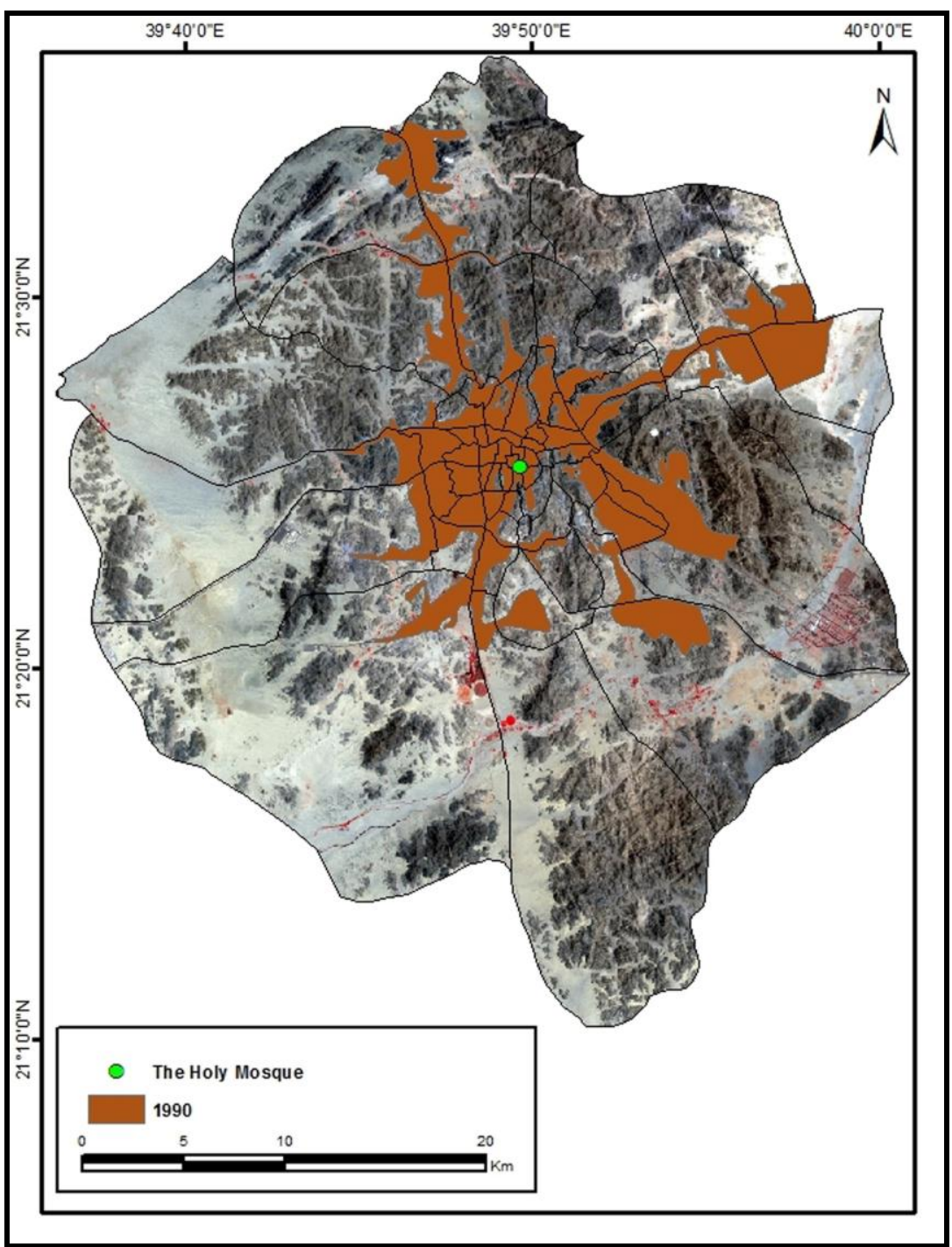

Figure 6. Built-up area of Makkah: 1990.

The urban sprawl ranged from one to two kms to the NE, WNW, and NW. In the NE, it filled spaces in the districts of Al-Khansa and Jabal AlNur. To the WNW, the sprawl spread into the spaces left in the As Salama district. In the NW, it filled other spaces in the Al-Zahir district.

The urban sprawl reached less than one $\mathrm{km}$ to the N, ENE, E, ESE, SE, SSE, S, SSW, SW, and W. In the N, the growth extended into spaces in the At Taniem district. To the ENE, the sprawl filled spaces in the Ar Rashidiyyah 
district. In the E, it filled spaces in the Al-Aziziyyah district. To the ESE, the growth filled spaces in the Al-Mursalat district. In the SE, the sprawl filled spaces in the districts of An Nasim and Al-Awali. To the SSE, it filled spaces in the Ar Rawabi, Kuday, and Al-Hijrah districts. In the S, the growth filled spaces in the Batha Quraysh district. To the SSW, it filled spaces in the Waly Al-Ahd district. In the SW, the sprawl filled spaces in the districts of Al-Khalidiyyah, Ash Shawqiyyah, and Al-Malik Fahd. To the W, the growth also filled spaces in the Al-Rusayfah and Umm Al-Jud districts (Figures 7 \& 8).

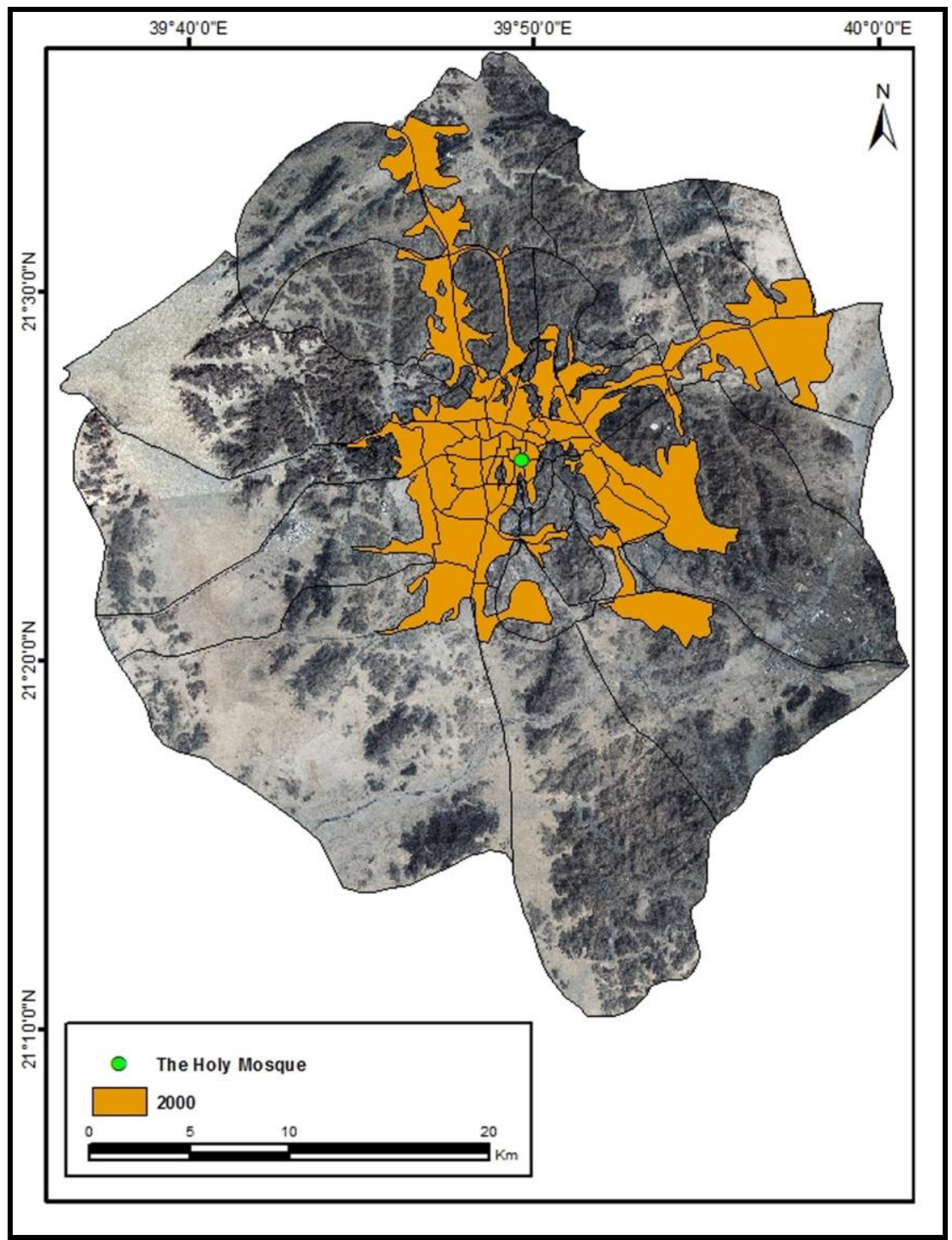

Figure 7. Built-up area of Makkah: 2000. 


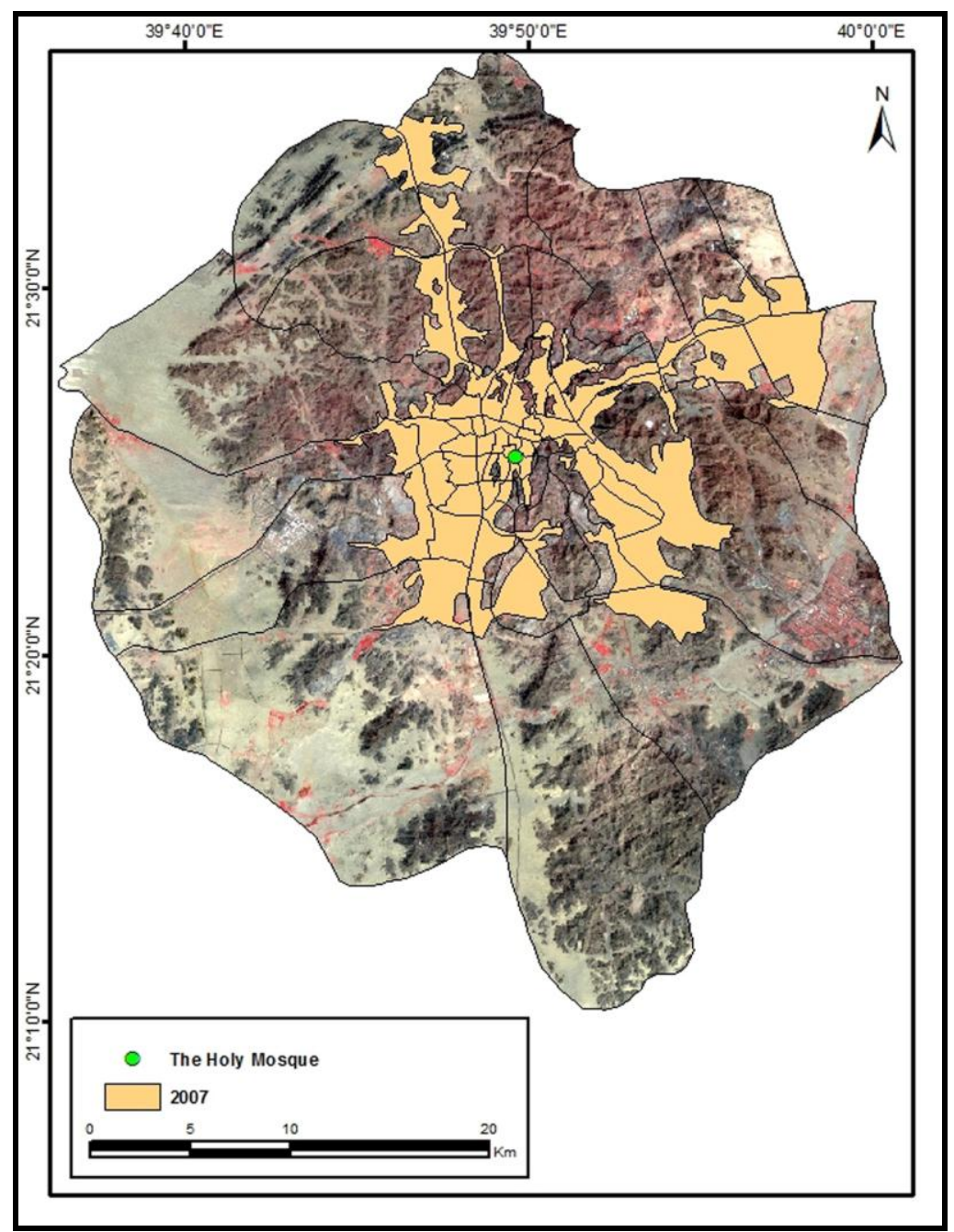

Figure 8. Built-up area of Makkah: 2007.

\section{- Second Urban Boom Stage (2007-2013)}

The relatively extensive growth in urban sprawl during this stage reached more than $10 \mathrm{kms}$ in two directions (SSE and W). To the SSE, the sprawl filled spaces in the Al-Hijrah and Al-Awali districts. In the W, it filled spaces in the districts of Al-Rusayfah and Umm Al-Jud.

The urban sprawl ranged from five to $10 \mathrm{kms}$ to the SW and WSW. In the SW, the growth filled spaces in the Al-Khalidiyyah, Ash Shawqiyyah, and Al-Malik Fahd districts. To the WSW, it filled spaces in the Al-Rusayfah and Al-Malik Fahd districts. 
The incremental growth of urban sprawl ranged from one to five $\mathrm{km}$ to the ENE, ESE, SE, WNW, and NW. In the ENE, the sprawl filled spaces in the Ar Rashidiyyah district. To the ESE, it filled spaces in the Al-Mursalat district. In the SE, the growth filled spaces in the districts of An Nasim and Al-Awali. To the WNW, it filled spaces in the As Salama district, while, in the NW, it filled spaces in the Al-Buhayrat district.

The urban sprawl reached less than one km to the N, NNE, NE, S, SSW, and NNW. In the N, the sprawl extended into the Al-Umrah district. To the NNE, it filled spaces in the Wadi Jalil district. In the NE, the sprawl expanded in the Sharai Al-Mojahedin district. To the S, it filled spaces in the Batha Quraysh district. In the SSW, the growth filled in spaces in the districts of Al-Kakiyyah and Waly Al-Ahd. To the NNW, it filled spaces in the AlBuhayrat and An Nawwariyyah districts (Figure 9).

The most important characteristic of urban growth during this stage was expantion to the planned districts that occupied spaces starting from the SE and moving toward the $\mathrm{W}$. This growth was associated with the Al-Taif and Jiddah roads (Appendix $1 \&$ Figure 10).

\section{Development of Added Built-up Areas}

The built-up area of Makkah during its early stage covered about $25 \mathrm{~km}^{2}$ or $8.9 \%$ of the built-up area in 2013 . About $130 \mathrm{~km}^{2}$ were urbanized during the first urban boom stage (1972-1990), covering about $155 \mathrm{~km}^{2}$, which represented about $55 \%$ of the built-up area in 2013. This expansion occurred because of the increased migration from both inside and outside of the KSA that accompanied the oil boom reflected by urban developments. During the retreat stage (1990-2007), the city added only $38 \mathrm{~km}^{2}$, increasing the city's area to $193 \mathrm{~km}^{2}$ or $68.7 \%$ of the built-up area in 2013 . In the second urban boom stage (2007-2013), further development added about $88 \mathrm{~km}^{2}$ to the built-up area and thereby increased its area to $281 \mathrm{~km}^{2}$, a figure which represents the cumulative value of urban growth since the city's origin up to 2013. This last expansion was due to developmental activities concentrated primarily in the city's planned districts (Table 8).

Table 8. Development stages for Makkah (1972-2013).

\begin{tabular}{|l|c|c|c|}
\hline \multirow{2}{*}{ Stage } & \multicolumn{2}{|c|}{ added area } & annual rate of addition \\
\cline { 2 - 4 } & $\mathbf{K m}^{\mathbf{2}}$ & $\mathbf{\%}$ & $\mathbf{\mathbf { K m } ^ { 2 }} / \mathbf{y e a r}$ \\
\hline until 1972 & 25 & 8.9 & - \\
\hline $1972-1990$ & 130.15 & 46.3 & 7.2 \\
\hline $1990-2007$ & 37.93 & 13.5 & 2.2 \\
\hline $2007-2013$ & 88.06 & 31.3 & 14.7 \\
\hline Total area $\mathbf{2 0 1 3}$ & $\mathbf{2 8 1 . 1 4}$ & $\mathbf{1 0 0 \%}$ & - \\
\hline
\end{tabular}

Source: Calculated by the author from satellite images of the city $(1972,1990,2007,2013)$. 


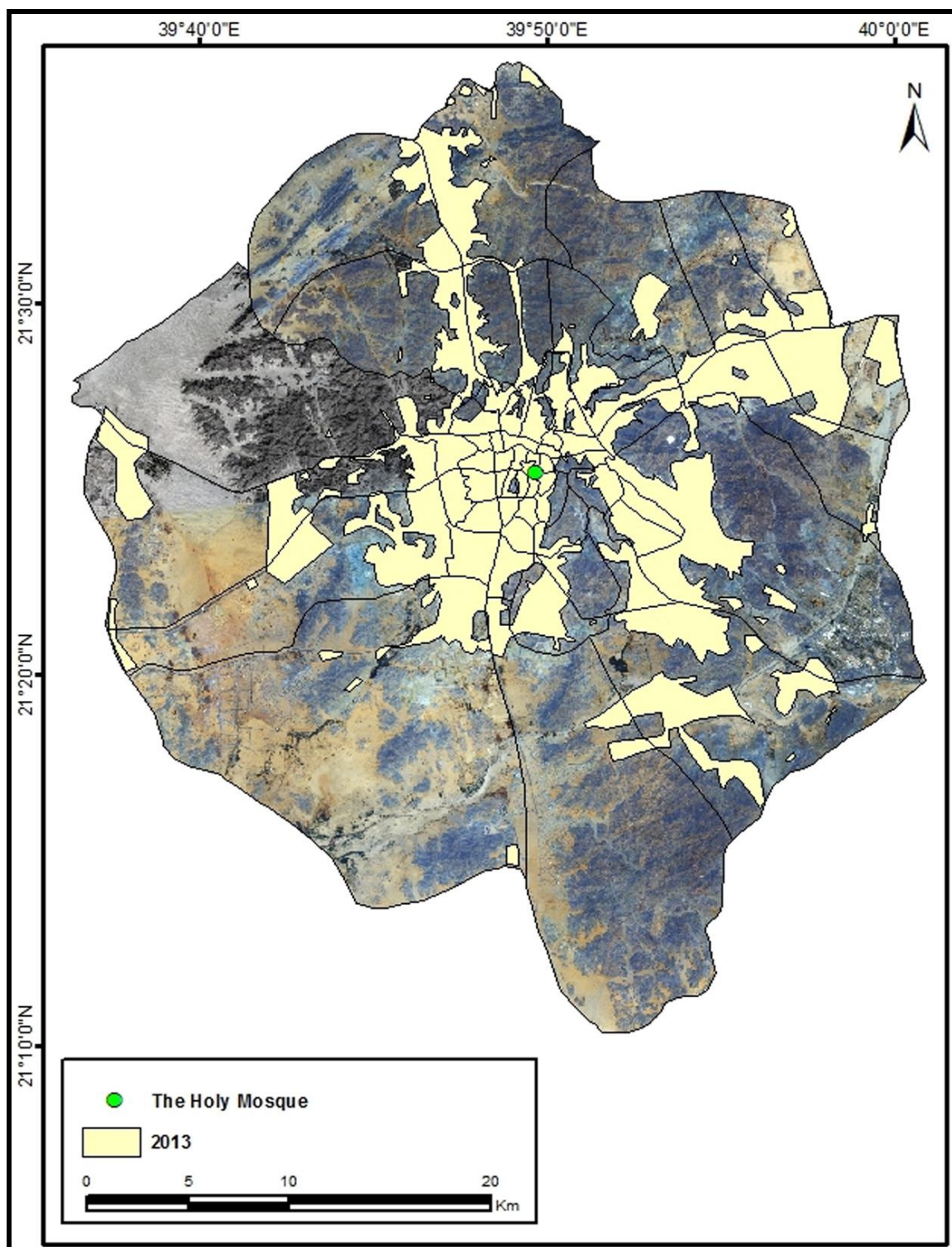

Figure 9. Built-up area of Makkah: 2013. 


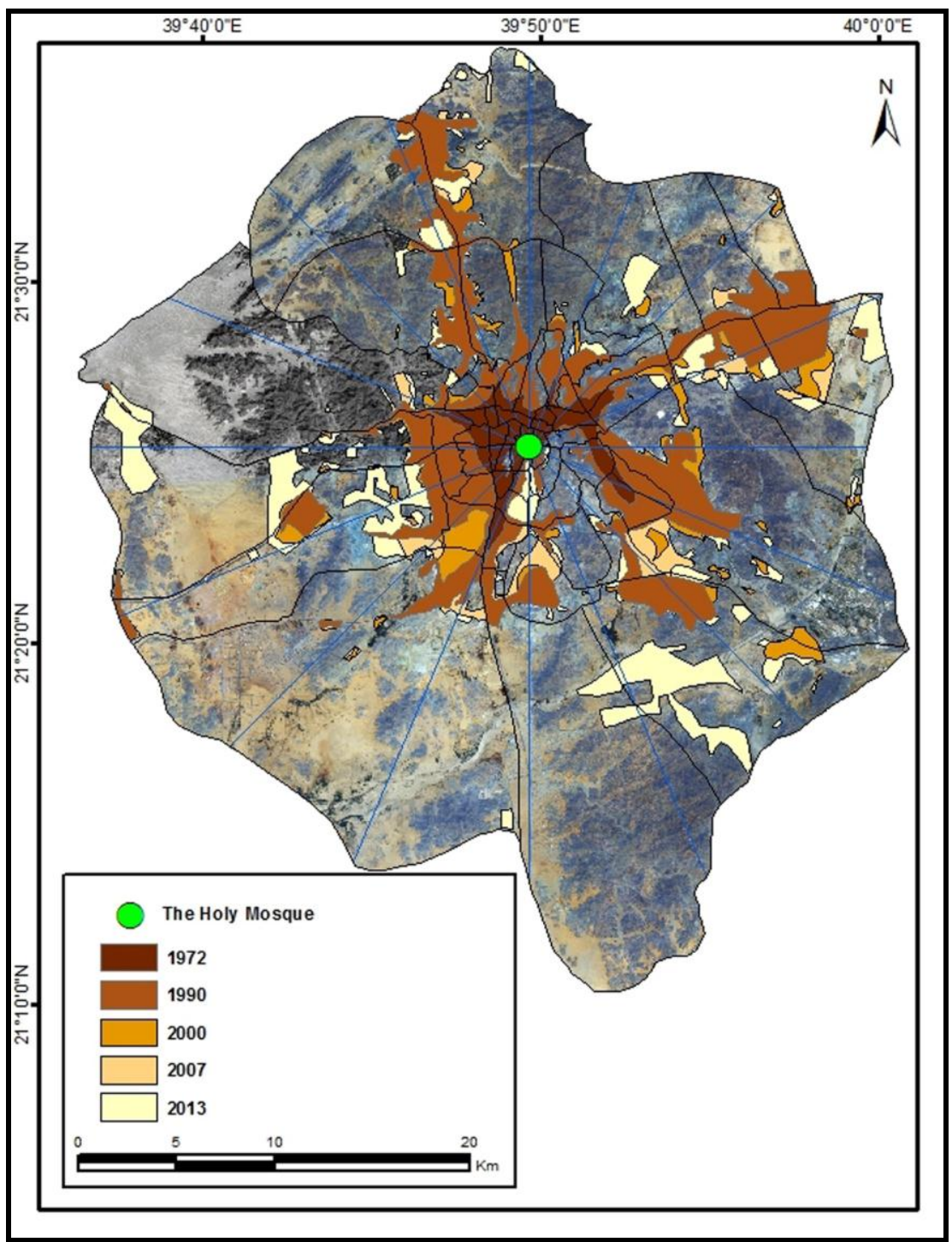

Figure 10. Built-up area of Makkah: 1972-2013.

The research's findings reveal that nearly half of the area added to the city's built-up area (46.3\% of the area in 2013) was developed during the first urban boom stage (1972-1990). Another large portion was added (31.3\% of the area in 2013) during the second urban boom stage (2007-2013).

The data on annual rates of growth in the city's built-up area emphasize that the city experienced the highest rate of added areas during the second 
urban boom stage when the rate reached $14.7 \mathrm{~km}^{2} /$ year. In contrast, the rate during the first urban boom stage was only $7.2 \mathrm{~km}^{2} /$ year, while the retreat stage had the lowest rates of additions to the built-up area.

\section{Directions of Urban Growth}

\section{- Horizontal Urban Growth Rates}

The characterization of urban growth rates in terms of geographical directions has benefits that reverberate in the urban planning of cities. This approach is useful in identifying the incentives to develop urban areas versus the obstacles presented by other areas (Meselhy, 2009). According to the data presented in Table (9), the general horizontal urban growth rate in the city under study reached 3,487 meters/year, with the average horizontal urban growth rate reaching its highest values during the second urban boom stage (2007-2013) at 575 meters/year. During the first urban boom stage (1972$1990)$, the rate was only 271.7 meters/year.

Table 9. Horizontal growth rate (urban sprawl) in the geographical directions (1972-2013).

\begin{tabular}{|l|c|c|c|c|c|}
\hline Period & $\mathbf{1 9 7 2 - 1 9 9 0}$ & $\mathbf{1 9 9 0 - 2 0 0 0}$ & $\mathbf{2 0 0 0 - 2 0 0 7}$ & $\mathbf{2 0 0 7 - 2 0 1 3}$ & Total \\
\hline Direction & Meter & Meter & Meter & Meter & Meter \\
\hline N & 178.9 & 36.6 & 10.6 & 7.5 & 90.3 \\
\hline NNE & 55.4 & 196.7 & 12.4 & 13.3 & 76.4 \\
\hline NE & 76.8 & 4.9 & 193.7 & 1.7 & 68.2 \\
\hline ENE & 705.9 & 2.8 & 4.1 & 415.5 & 372.1 \\
\hline E & 255.7 & 45 & 18 & 0 & 126.3 \\
\hline ESE & 290 & 5.3 & 1.6 & 365.2 & 182.3 \\
\hline SE & 662 & 9.8 & 2.3 & 791.3 & 409.2 \\
\hline SSE & 204.4 & 5.9 & 2.9 & $1,773.8$ & 351.3 \\
\hline S & 408.9 & 2.8 & 0 & 11 & 181.8 \\
\hline SSW & 157.9 & 4.2 & 87.7 & 9.3 & 86.7 \\
\hline SW & 226.5 & 3.2 & 86 & $1,156.7$ & 284.2 \\
\hline WSW & 174.7 & 0 & 0 & $1,611.3$ & 312.5 \\
\hline W & 184.2 & 17.4 & 0 & $2,425.5$ & 440 \\
\hline WNW & 28.5 & 33.9 & 185.7 & 210.2 & 83.2 \\
\hline NW & 34.2 & 14.8 & 205.7 & 311 & 99.3 \\
\hline NNW & 703.4 & 0 & 0 & 97.2 & 323 \\
\hline Total & $\mathbf{2 7 1 . 7}$ & $\mathbf{2 3 . 9}$ & $\mathbf{5 0 . 7}$ & $\mathbf{5 7 5}$ & $\mathbf{3 , 4 8 7}$ \\
\hline
\end{tabular}

Source: Calculated by the author based on appendix 1 and satalite images of the city $(1972,1990,2007,2013)$. 
The city's horizontal urban growth rates can be divided by overall rate into four groups:

- Group 1: Directions with horizontal urban growth rates of more than 400 meters/year, represented by the directions of SE and W.

- Group 2: Directions with horizontal urban growth rates ranging from 300 to 400 meters/year, including ENE, SSE, WSW, and NNW.

- Group 3: Directions with horizontal urban growth rates ranging from 200 to 300 meters/year, represented by the SW direction.

- Group 4: Directions with horizontal urban growth rates less than 200 meters/year, including all other directions.

Overall, the horizontal urban growth rates ranged in the first urban boom stage from 28.5 meters/year to the WNW to 705.9 meters/year to the ENE. In the second urban boom stage, the rates varied from 0 meter/year to the $\mathrm{E}$ to $2,425.5$ meters/year to the $\mathrm{W}$.

The above analysis makes clear that the highest horizontal urban growth rates are represented by those in the $\mathrm{W}, \mathrm{SW}$, and SE because urban sprawl in these directions was in the planned districts that occupied spaces, starting from the SE direction and moving toward the $\mathrm{W}$ direction, associated with the Al-Taif, Al-Laith and Jiddah roads. This research indicates that horizontal growth will continue in the future along those directions.

\section{- Added Value to Built-up Area in Geographical Directions}

The percentage distribution of horizontal urban growth directions in the city (Table 10 \& Figure 11) emphasize that the rate was highest in the $\mathrm{W}$ (10.7\%) compared to the cumulative growth in all directions-followed by growth rates in the ENE (9.9\%) and then the SE (9\%). The proportions decreased in the remaining directions of the city to less than $9 \%$ for each direction.

A combination of factors has contributed either directly or indirectly to the city's urban sprawl. The mountains are an important influencing natural factor, which is directly responsible for aspects of the city's urban growth particularly in the first stage (Figures 12 and 13), when the areas surrounding the Holy Mosque were developed. The prosperity achieved by the KSA since the beginning of the oil boom resulted in the development of new activities such as digging tunnels through the mountains. Thus, aspects of the city's urban growth changed after overcoming these mountain barriers (Picture 1). The construction of several roads across the mountains has facilitated access to the city from all directions, as well as urban development along these roads. 
Table 10. The percentage distribution of the cumulative growth in different geographical directions for Makkah (1972-2013).

\begin{tabular}{|l|c|c|c|c|c|c|}
\hline \multicolumn{1}{|c|}{ Period } & $\begin{array}{c}\text { until } \\
\mathbf{1 9 7 2}\end{array}$ & $\begin{array}{c}\mathbf{1 9 7 2 -} \\
\mathbf{1 9 9 0}\end{array}$ & $\begin{array}{c}\mathbf{1 9 9 0 -} \\
\mathbf{2 0 0 0}\end{array}$ & $\begin{array}{c}\mathbf{2 0 0 0 -} \\
\mathbf{2 0 0 7}\end{array}$ & $\begin{array}{c}\mathbf{2 0 0 7 -} \\
\mathbf{2 0 1 3}\end{array}$ & $\begin{array}{c}\text { \% of } \\
\text { cumulative } \\
\text { growth }\end{array}$ \\
\hline Direction & $\mathbf{\%}$ & $\mathbf{\%}$ & $\mathbf{\%}$ & $\mathbf{\%}$ & $\mathbf{\%}$ & 2.9 \\
\hline N & 3.9 & 4.1 & 9.5 & 1.3 & 0.1 & 3.6 \\
\hline NNE & 7.4 & 1.3 & 51.3 & 1.5 & 0.1 & 3.4 \\
\hline NE & 7.4 & 1.8 & 1.3 & 23.9 & 0.0 & 9.9 \\
\hline ENE & 7.8 & 16.2 & 0.7 & 0.5 & 4.5 & 4.7 \\
\hline E & 7.6 & 5.9 & 11.7 & 2.2 & 0.0 & 6.9 \\
\hline ESE & 11.7 & 6.7 & 1.4 & 0.2 & 4.0 & 9.0 \\
\hline SE & 1.1 & 15.2 & 2.6 & 0.3 & 8.6 & 7.7 \\
\hline SSE & 1.1 & 4.7 & 1.5 & 0.4 & 19.3 & 4.2 \\
\hline S & 1.2 & 9.4 & 0.7 & 0.0 & 0.1 & 4.8 \\
\hline SSW & 11.4 & 3.6 & 1.1 & 10.8 & 0.1 & 7.3 \\
\hline SW & 5.1 & 5.2 & 0.8 & 10.6 & 12.6 & 7.9 \\
\hline WSW & 5 & 4.0 & 0 & 0.0 & 17.5 & 10.7 \\
\hline W & 5.5 & 4.2 & 4.5 & 0.0 & 26.4 & 4.3 \\
\hline WNW & 9.7 & 0.7 & 8.8 & 22.9 & 2.3 & 3.8 \\
\hline NW & 6.6 & 0.8 & 3.9 & 25.4 & 3.4 & 8.9 \\
\hline NNW & 7.7 & 16.2 & 0 & 0 & 1.1 & $\mathbf{1 0 0}$ \\
\hline Total & $\mathbf{1 0 0}$ & $\mathbf{1 0 0}$ & $\mathbf{1 0 0}$ & $\mathbf{1 0 0}$ & $\mathbf{1 0 0}$ & \\
\hline SW & & & & & & \\
\hline
\end{tabular}

Source: Calculated by the author based on appendix 1 and satalite images of the city (1972, 1990, 2007, 2013).

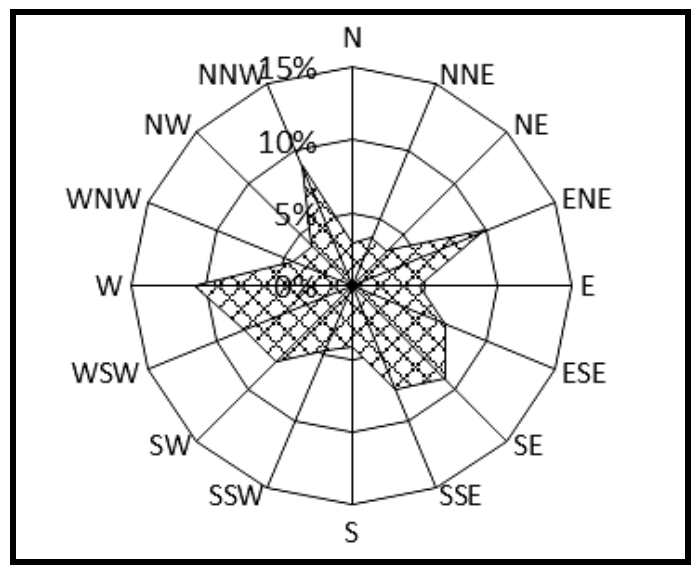

Figure 11. Geographical directions of horizontal urban growth in Makkah city since its origin up to 2013. 
Migrations from inside and outside the KSA have an important role in the city's growth since migrants prefer to live in certain districts with compatriots who immigrated earlier to the city. The concentration of populations in the old city according to migrants' ethnic origins has resulted in slums.

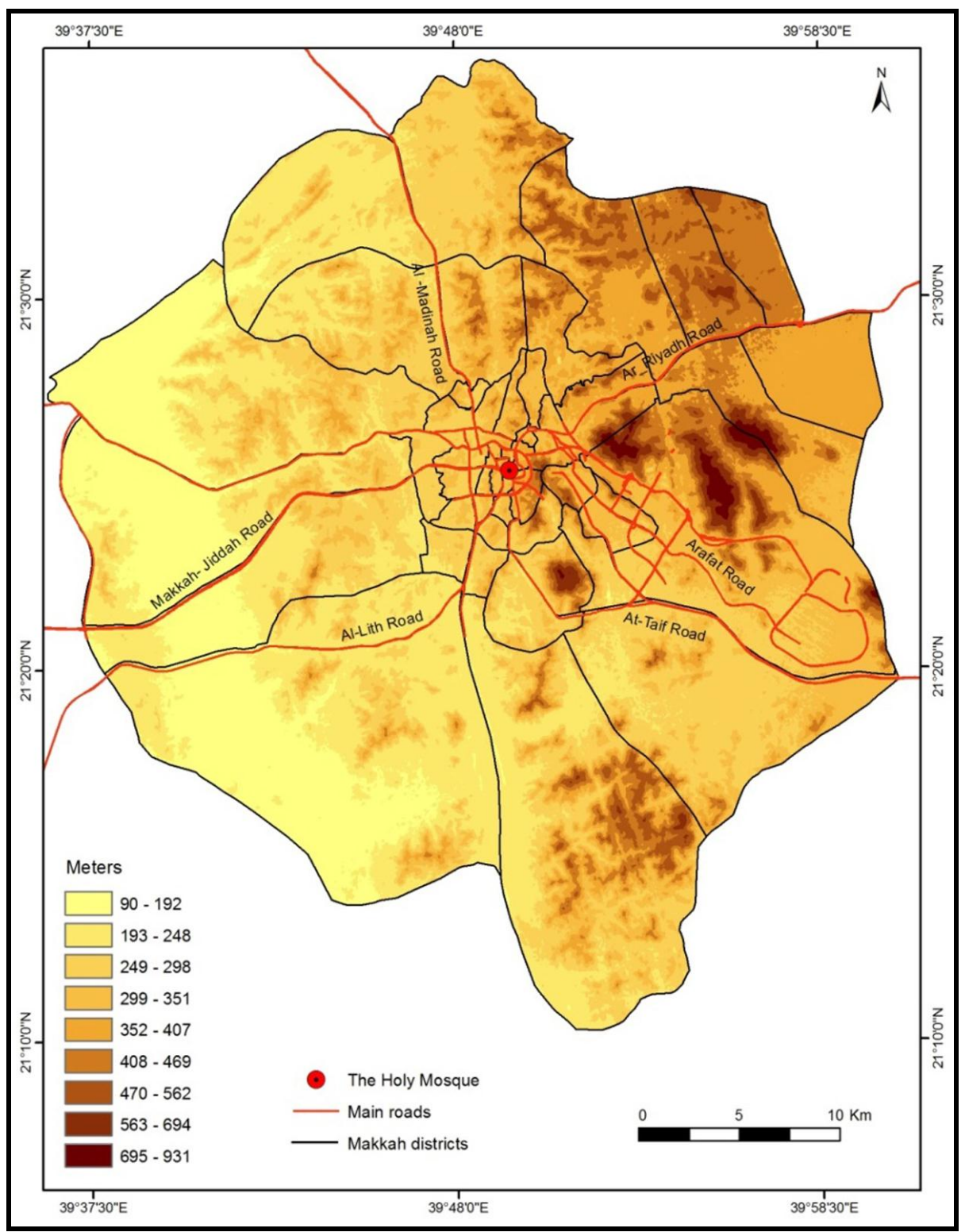

Figure 12. Topography of Makkah city. 


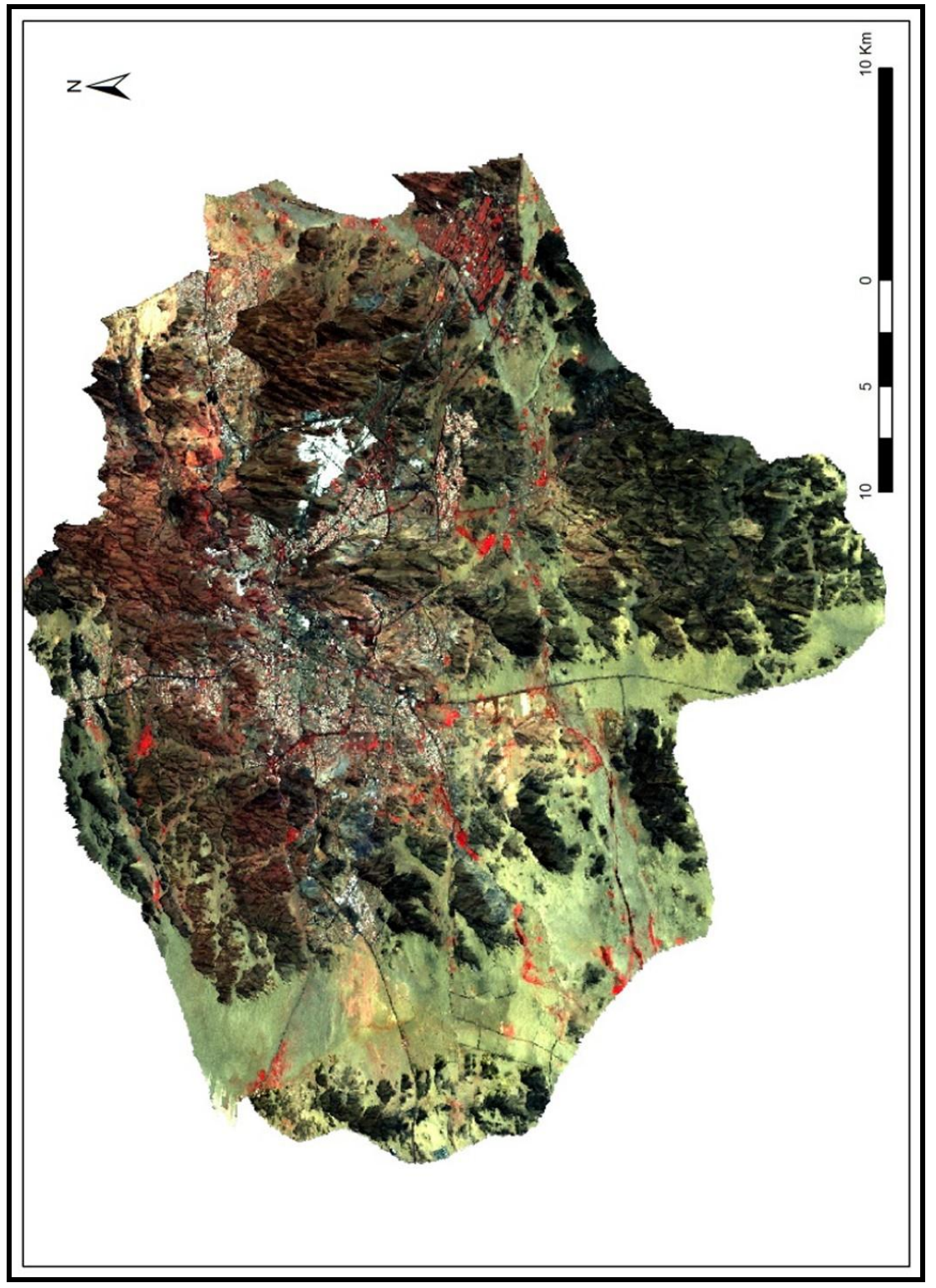

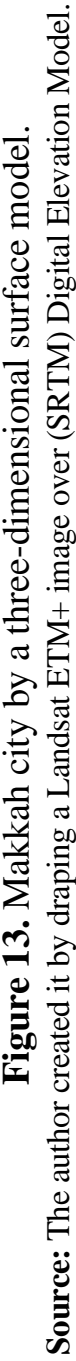



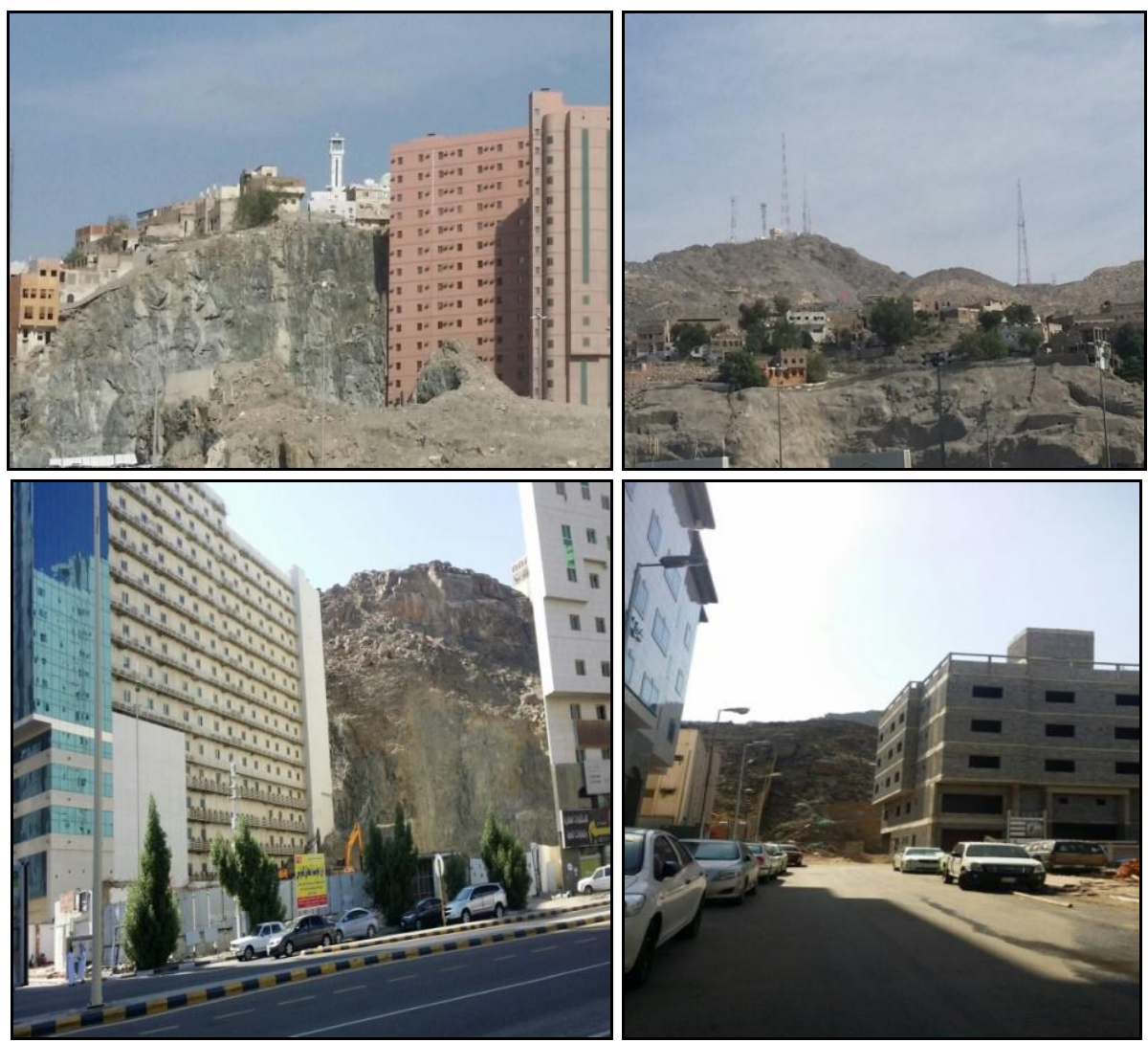

Source: The field work, 2014.

Picture 1. Urban sprawl toward the mountainous areas in Makkah city.

Successive projects expanding the Holy Mosque have led to the demolition of some parts of the old districts surrounding the Holy Mosque. This has resulted in population movements from the central business district toward the new planned districts, causing further changes in aspects of urban growth. In addition, the Umm Al-Qura University has played an important role in the city's urban expansion since this institution has spurred the growth of the Al-Aziziyyah and Al-Awali districts.

\section{Added Rates of The Built-up Area of Makkah}

The data in Table (11) indicate that the city's built-up area doubled in size during the first urban boom stage or about five times the space occupied in 1972 (the base year). Then, during the retreat stage, the area doubled again to about seven times the area in the base year, and then doubled once more during the second urban boom stage to 10 times the area in the base year. 
Table 11. Cumulative value of the built-up area and number of times the value doubled.

\begin{tabular}{|c|c|c|}
\hline Stage & $\begin{array}{c}\text { Built-up area } \\
\left(\mathbf{k m}^{\mathbf{2}}\right)\end{array}$ & $\begin{array}{c}\text { Growth index of } \\
\text { built-up area (\%) }\end{array}$ \\
\hline Until 1972 & 25 & 100 \\
\hline $1972-1990$ & 155.15 & 620.6 \\
\hline $1990-2000$ & 174.47 & 697.9 \\
\hline $2000-2007$ & 193.08 & 772.3 \\
\hline $2007-2013$ & 281.14 & $1,124.6$ \\
\hline
\end{tabular}

Source: Calculated by the author based on satalite images of the city $(1972,1990,2007,2013)$.

\section{Evolution of Population and Urban Growth}

This section seeks to blend data on urban and population growth showing Makkah's evolution over time, to analyze the relationship between them, and to identify the extent of the built-up area's capacity to absorb population increases. This indicates the extent of the balance between supply (urban growth) and demand (population growth), as well as revealing the evolution of urban density, including the per capita of urban clusters, which helps to identify population densification processes.

The city has experienced an urban and population boom since the 1970s due to increased migration associated with the oil boom, from inside and outside of the KSA. With the construction of car tunnels that ended the natural barriers between the Holy Mosque and other holy sites, the city has experienced significant prosperity, including expanded urbanism along the main roads and the appearance of planned districts in all areas. Developmental activities have concentrated primarily in these planned districts.

According to the data shown in Table (12), the city's population size increased from 733,761 in 1990 to $1,654,877$ in 2013 . Thus, its population size more than doubled, or 2.25 times, during a quarter of a century, while its built-up area almost doubled during the same period, or about 1.81 times.

Based on an analysis of Makkah's periods of changing urban and population development (Figure 14), the city's population growth was greater than its urban growth during the periods of 1990-2000 and 2000-2007. However, during the last period studied (2007-2013), urban growth was greater than population growth, which indicates that the city's population has 
not had to complain about a lack of urban space. This means that no housing problem currently exists in the city as a result of a greater supply than demand, which is confirmed by the indicators of evolution of the city's population and built-up area. Therefore, the city will be able to accommodate a higher population in the future.

Table 12. Developmental indicators of Makkah's population size and built-up area (1990-2013).

\begin{tabular}{|c|c|c|c|c|c|c|c|c|}
\hline$\stackrel{\Xi}{\Xi}$ & & 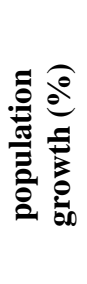 & 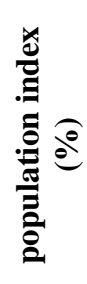 & 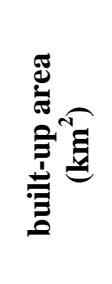 & 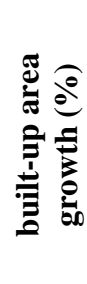 & 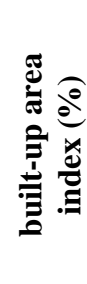 & 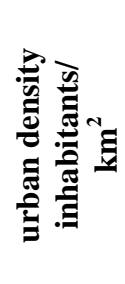 & 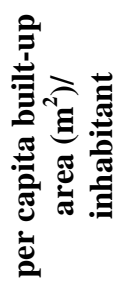 \\
\hline 1990 & 733,761 & - & 100 & 155.15 & - & 100 & $4,729.4$ & 211.4 \\
\hline 2000 & $1,134,246$ & 4.45 & 154.6 & 174.47 & 1.18 & 112.4 & $6,501.1$ & 153.8 \\
\hline 2007 & $1,414,586$ & 3.21 & 192.8 & 193.08 & 1.46 & 124.4 & $7,326.4$ & 136.5 \\
\hline 2013 & $1,654,877$ & 2.65 & 225.5 & 281.14 & 6.46 & 181.2 & $5,886.3$ & 169.9 \\
\hline
\end{tabular}

Source: Calculated by the author from satalite images of the city(1990, 2007, 2013).

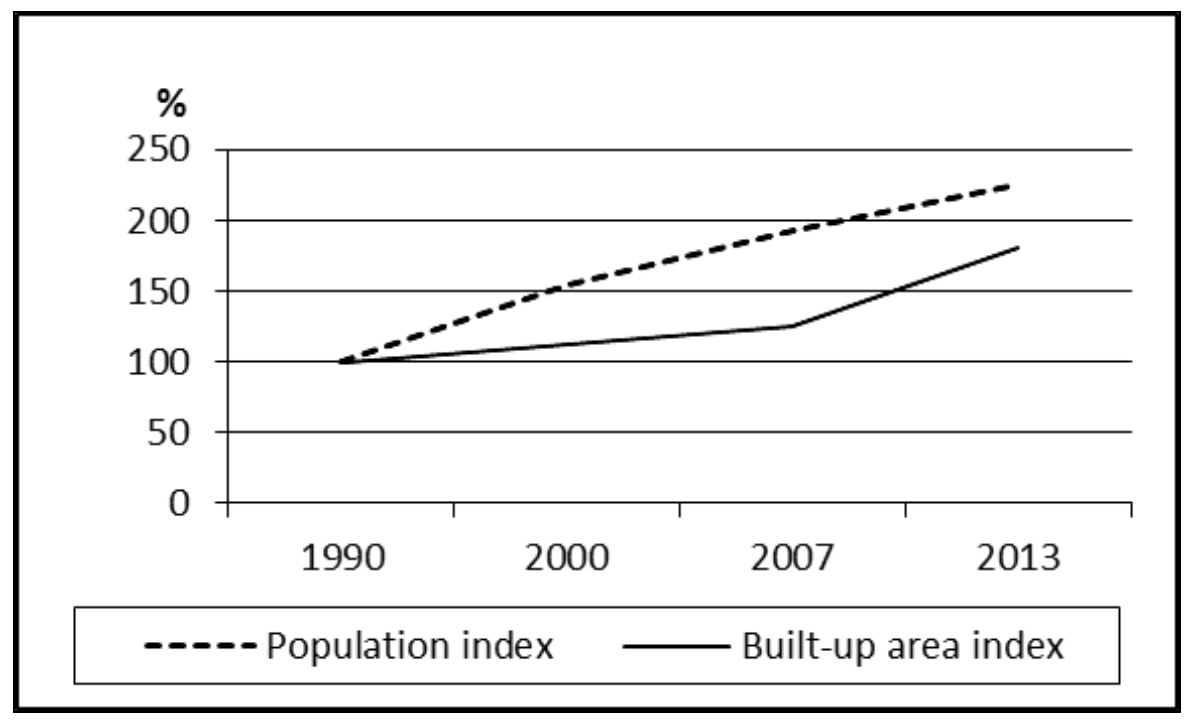

Figure 14. Developmental indicators of Makkah's population and built-up area (1990-2013). 
The data shown in Table (12) reveal clearly that the city's urban density increased from 4,729.4 inhabitants $/ \mathrm{km}^{2}$ in 1990 to $7,326.4$ inhabitants $/ \mathrm{km}^{2}$ in 2007 (the retreat stage). Then, the density decreased to 5,886.3 inhabitants $/ \mathrm{km}^{2}$ in 2013 (the second urban boom stage). This can be explained by how the continuing flow of immigrants from inside and outside the KSA to the city was not offset by the city's urban growth during the retreat stage. During the second urban boom stage, the greater urban growth compared to population growth, resulting from the building of new planned districts, allowed the population to occupy a larger urban area in the city.

An analysis of the per capita built-up area (Table 12) shows that the per capita built-up area decreased from 211.4 square meters $\left(\mathrm{m}^{2}\right) /$ inhabitant, in 1990 , to $136.5 \mathrm{~m}^{2} /$ inhabitant, in 2007 . It then increased to 169.9 $\mathrm{m}^{2} /$ inhabitant, in 2013 .

\section{Population Size (1990-2013)}

Based on Appendix 2, Makkah's districts can be divided into five groups according to the geographical distribution of their population from 1990 to 2013, as follows:

- Group 1: Districts having a population of less than 10,000: This group included 31 districts, in 1990, but this number dropped to 20 districts, in 2000, and then fell further to 13, in 2007 and 10, in 2013, due to increases in population size causing districts to move to a higher category.

- Group 2: Districts having a population ranging from 10,000 to 30,000 included 28 districts, in 1990, but declined to 25, in 2013.

- Group 3: Districts having a population ranging from 30,000 to 50,000 experienced a continuous increase from one district, in 1990 (AlHindawiyyah with 44,482 people), to 17 districts, in 2013 , due to the aforementioned factors.

- Group 4: Districts with a population ranging from 50,000 to 70,000. This group had also experienced a steady increase from one district only (Al-Hindawiyyah with 63,112 people), in 2000, to seven districts, in 2013. These are Al-Tandabawi, Al-Taqwa, Al-Khalidiyyah, Ar Rashidiyyah, Al-Andalus, Al-Zahra, and Al-Jamiah.

- Group 5: Districts with a population of more than 70,000 included only one such district in 2007 (Al-Hindawiyyah with 76,153 people), and continued to grow to 87,331 in 2013 .

\section{Built-up Area (1990-2013)}

Based on the data presented in Appendix (2), Makkah's districts can be divided into five groups according to the geographical distribution of built-up areas from 1990 to 2013, as follows: 
- $\quad$ Group 1: Districts each have less than 500 acres of built-up area. This group included 29 districts, in 1990, but this number declined gradually until it reached 25, in 2013.

- Group 2: Districts ranging from 500 to 1,000 acres included 19 districts, in 1990, and 2007, but dropped to 16, in 2013.

- Group 3: Districts ranging from 1,000 to 1,500 acres included seven districts in 1990, but declined to five, in 2007. However, the number rose back to seven, in 2013.

- Group 4: Districts ranging from 1,500 to 2,000 acres included only three districts, in 1990, and continued without change until 2013.

- Group 5: Districts with a built-up area of more than 2,000 acres included only two districts, in 1990 (Al-Mashair and Ar Rashidiyyah), to which were add two more (Al-Awali and Al-Umrah), in 2000. Waly AlAhd and Ash Sharai districts were added, in 2007, and continued to rise until it reached nine, in 2013, by adding the districts of Al-Malik Fahd, Al-Buhayrat, and Umm Al-Jud. This growth was due to new planned districts development during the second urban boom stage, which occupied large urban areas in the city.

\section{Urban Density (1990-2013)}

Based on an analysis of the data shown in Appendix 2, Makkah's districts can be divided into five groups according to the geographical distribution of urban density from 1990 to 2013, as follows:

- Group 1: Districts having an urban density of less than 25 inhabitants/acre included 31 districts, in 1990, but dropped to 22, in 2000, and to 20, in 2007, which continued until 2013.

- Group 2: Districts having an urban density ranging from 25 to 50 inhabitants/acre included 19 districts in 1990, continued until 2000 but dropped to 15, in 2007, and 10 districts in 2013.

- Group 3: Districts have an urban density ranging from 50 to 75 inhabitants/acre. This group has continuously grown from four, in 1990, to 13 , in 2013.

- Group 4: Districts have an urban density ranging from 75 to 100 inhabitants/acre. This group has experienced a continuous expansion from three districts, in 1990, to seven, in 2013.

- Group 5: Districts have an urban density of more than 100 inhabitants/acre. This group started with three districts in 1990 (AlTandabawi, Al-Misfalah, and Al-Taqwa). Then, four other districts were added, in 2000 (Al-haram \& Al-Hajlah, Al-Shubaikah, Al-Hindawiyyah, and Al-Zahra). A further three districts were added (Al-Mansur, AlHujun, and Al-Khansa), and this number continued until 2013. 


\section{Per Capita Built-up Area (1990-2013)}

The data in Appendix 2 also allows Makkah's districts to be divided into four groups according to the geographical distribution of per capita built-up area from 1990 to 2013, as follows:

- Group 1: Districts having a per capita built-up area of less than 100 $\mathrm{m}^{2} /$ person included 11 districts, in 1990, which then increased to 32 districts, in 2013.

- Group 2: Districts with a per capita built-up area from 100 to 300 $\mathrm{m}^{2} /$ person included 31 districts, in 1990, but decreased gradually until the number reached 14, in 2013.

- Group 3: Districts have a per capita built-up area from 300 to 500 $\mathrm{m}^{2} /$ person included seven districts, in 1990 , but increased to nine, in 2000, and then began to decline until it reached six districts, in 2013.

- Group 4: Districts having a per capita built-up area of more than 500 $\mathrm{m}^{2} /$ person included 11 districts, in 1990, then decreased to three, in 2007. The number rose again to eight, in 2013, with the Al-Awali, AlMashair, Al-Malik Fahd, Batha Quraysh, Al-Osailah, Sharai AlMojahedin, An Nawwariyyah, and Umm Al-Jud districts.

\section{Future of Population and Built-up Area}

This section seeks to develop future scenarios for the city under study with regard to population and built-up area. The research results are used to estimate the city's population size and determine its future trends in urban growth.

\section{Future Population Size}

To estimate the city's population in the future (until 2035), three different hypotheses are used to formulate a high, medium, and low estimations. Future trends are likely to fall within the range between high and low hypotheses, but the research's findings indicate that the medium hypothesis should be used for predictions. Projection assumptions are usually based on analyses of recent demographic trends, with the exclusion of major abnormal events, such as war and political upheavals (Woods, 1979).

Based on an analysis of the city's population growth rates over four decades, the medium estimate was calculated using an assumed constant population growth rate at $2.94 \%$, based on the last census period (20042010). The low estimate was calculated by lowering the city's population growth rate to $2.44 \%$, while the high estimate was calculated based on the assumption that the population growth rate could reach $3.44 \%$. The same 
method was followed to estimate the population size of the region and the KSA (Table 13 and Figure 15).

As Table (13) show, the city's population is expected to be 3,170,199 in 2035, according to the medium estimate (Figure 14). The population was $1,534,731$ in 2010 , so this is a projected increase of $1,635,468$ people, which is equivalent to $106.6 \%$ of the city's population size in 2010 . In addition, an analysis of the population projections based on low and high estimates showed that the city's population at the end of the projection period (2035) will range from $2,806,880$ to $3,578,434$.

Table 13. Future estimates of Makkah's population size (until 2035).

\begin{tabular}{|c|c|c|c|}
\hline \multirow{2}{*}{ Year } & \multicolumn{3}{|c|}{$\begin{array}{c}\text { projections based on hypotheses } \\
\text { of population growth }\end{array}$} \\
\cline { 2 - 4 } & High & Medium & Low \\
\hline 2015 & $1,817,877$ & $1,774,366$ & $1,731,692$ \\
\hline 2020 & $2,153,261$ & $2,051,417$ & $1,953,930$ \\
\hline 2025 & $2,550,520$ & $2,371,728$ & $2,204,688$ \\
\hline 2030 & $3,021,071$ & $2,742,052$ & $2,487,629$ \\
\hline 2035 & $3,578,434$ & $3,170,199$ & $2,806,880$ \\
\hline
\end{tabular}

Source: Calculated by the author based on population census, 2010.

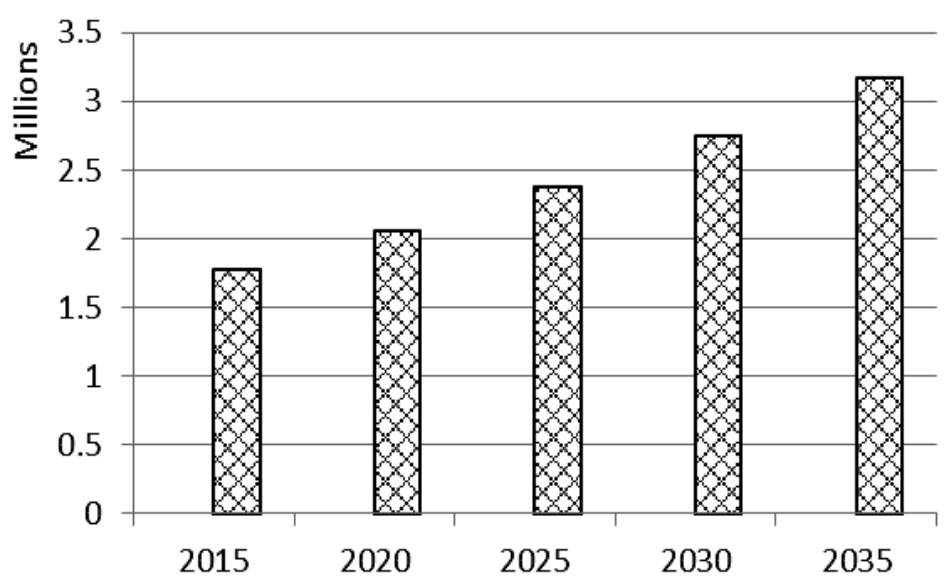

Figure 15. Future population size of Makkah according to the medium estimate (until 2035). 


\section{Future of The Geographical Distribution of The Population (2015-2035)}

Based on the data shown in Appendix (3), Makkah's districts can be divided into five groups according to the geographical distribution of the population from 2015 to 2035 , as follows:

- Group 1: These districts' future population is expected to remain stable, according to a medium estimate of less than 10,000. This group will include nine districts in 2015. Then, its numbers will decline gradually until it reaches the end of the projection period to three districts only, including Al-Qararah \& Naqqa, Al-Mashair, and Al-Osailah.

- Group 2: These districts' future population is expected to range, according to the medium estimate, from 10,000 to 30,000. This group will include 23 districts, in 2015 , after which the number will decline gradually until it reaches the end of the projection period and 17 districts.

- Group 3: These districts' future population size is expected to range, according to the medium estimate, from 30,000 to 50,000. This group will include 18 districts, in 2015, and then, this number will decline gradually until it reaches the end of the projection period and 10 districts.

- Group 4: These districts' future population size is expected to range, according to the medium estimate, from 50,000 to 70,000. This group will include eight districts, in 2015, and then, this number will increase gradually until it reaches the end of the projection period and 12 districts.

- Group 5: These districts' population size is expected to increase in the future, according to the medium estimate, to more than 70,000. This group will include only two districts, in 2015 (Al-Hindawiyyah, and AlJamiah), then the number of districts will increase gradually until the end of projection period is reached and the group has 18 districts.

\section{Future of Built-up Area}

Based on three estimates of future population growth, the city's population is expected to increase in the future based on the medium estimate. The medium hypothesis $(2.94 \%)$ is considered the most reliable for projections of the future of the city's urban and population growth until 2035.

According to the medium estimate, the city's population is projected to reach $3,170,199$, in 2035 . This means that the total added population during the period (2010-2035) will reach 1,635,468 (Table 14), which is equivalent to $106.6 \%$ of the city's population in 2010 . 
Without doubt, the city's responsibility to provide the required space in the built-up area that meets the requirements of the total increased population must be evaluated accurately, according to the expected average per capita built-up area. This projected ratio can be estimated from the developmental processes of the built-up area from 1972 to 2013, which involves three proposed alternatives:

- High alternative, which reflects only the city's period of rapid urban expansion, from 1972 to 1990 , or $300 \mathrm{~m}^{2} /$ person.

- Medium alternative, which suggests $189 \mathrm{~m}^{2} /$ person based on the entire period studied, from 1972 to 2013.

- Low alternative, which refers to the period of decline in the city's urban expansion, from 1990 to 2007 , or $55.7 \mathrm{~m}^{2} /$ person.

According to the stage that the city has reached in urban and population growth, the medium alternative will most likely be used. The study's results (Table 14) clearly show that the projected urban space required in the future can be narrowed down to the most likely alternative of $62,812.5$ acres to resettle 1,395,833 people until 2035. This period can be divided into four sub-phases:

- $\quad$ Near-term (2015-2020): The urban space required during this period is $12,467.3$ acres to resettle 277,051 people $(55,410$ families $)$.

- $\quad$ Short-term (2020-2025): The urban space required during this period is 14,414 acres to resettle 320,311 people $(64,062$ families).

- Medium-term (2025-2030): The urban space required during this period is $16,664.6$ acres to resettle 370,324 people (74,065 families).

- Long-term (2030-2035): The urban space required during this period is $19,266.6$ acres to resettle 428,147 people $(85,629$ families $)$.

This population increase, which exceeds the city's population in 2010, will need development projects in the service sector in various fields (e.g., health, trade, and education). These will need to be exceptionally well planned, including expansions according to observed land use patterns.

Projections can be based on the above-mentioned findings and the city's composed horizontal urban growth map, which shows the areas that have been added to the nucleus area in different geographical directions and the relative proportion of the horizontal urban sprawl in each direction. A field study was also carried out that revealed no impediments to the city's horizontal urban growth in the future except in the east, where the holy sites are located. 
Table 14. Future additions to Makkah's population and built-up area (until 2035).

\begin{tabular}{|c|c|c|c|c|}
\hline \multirow{2}{*}{ Period } & \multirow{2}{*}{$\begin{array}{c}\text { addition in } \\
\text { population }\end{array}$} & \multicolumn{3}{|c|}{$\begin{array}{c}\text { urban area required according to the } \\
\text { proposed alternatives (acre) }\end{array}$} \\
\cline { 3 - 5 } & 239,635 & $17,116.8$ & $10,783.6$ & 3,178 \\
\hline $2010-2015$ & High & Medium & Low \\
\hline $2015-2020$ & 277,051 & $19,789.4$ & $12,467.3$ & $3,674.2$ \\
\hline $2020-2025$ & 320,311 & $22,879.4$ & 14,414 & $4,247.9$ \\
\hline $2025-2030$ & 370,324 & $26,451.7$ & $16,664.6$ & $4,911.2$ \\
\hline $2030-2035$ & 428,147 & $30,581.9$ & $19,266.6$ & 5,678 \\
\hline Total addition & $\mathbf{1 , 6 3 5 , 4 6 8}$ & $\mathbf{1 1 6 , 8 1 9 . 2}$ & $\mathbf{7 3 , 5 9 6 . 1}$ & $\mathbf{2 1 , 6 8 9 . 3}$ \\
\hline
\end{tabular}

Source: Calculated by the author, Acre $=4200 \mathrm{~m}^{2}$

Therefore, the results suggest that the best urban expansion area in the near-term (2015-2020) is the As Salama area, which is located in the WNW. As illustrated in Figure (16), this is one of the areas stimulating urban growth, and it will accommodate a population increase until 2020, estimated at 277,051 people (Table 14). In the short-term (2020-2025), the best option is Waly Al-Ahd, which is located in the SSW and is also one of the areas stimulating urban growth. This area will accommodate a population increase until 2025, estimated at 320,311 people. In the medium-term (2025-2030), the urban expansion area is Umm Al-Jud, which is located in the $\mathrm{W}$ and is a further district stimulating urban growth. This area will accommodate a population increase until 2030, estimated at 370,324 people. Finally, in the long-term (2030-2035), the best option is Al-Malik Fahd, which is located in the SW and WSW. This is one of the areas stimulating urban growth, and it will accommodate a population increase until 2035, estimated at 428,147 people.

The conflict between the city's urban and population growth will remain in case of a deficit in the growth of either aspect. If the population growth rate exceeds the urban growth rate, a housing problem will appear, and, if the converse happens, an excess of planned housing will develop or non-residential land use will expand. 


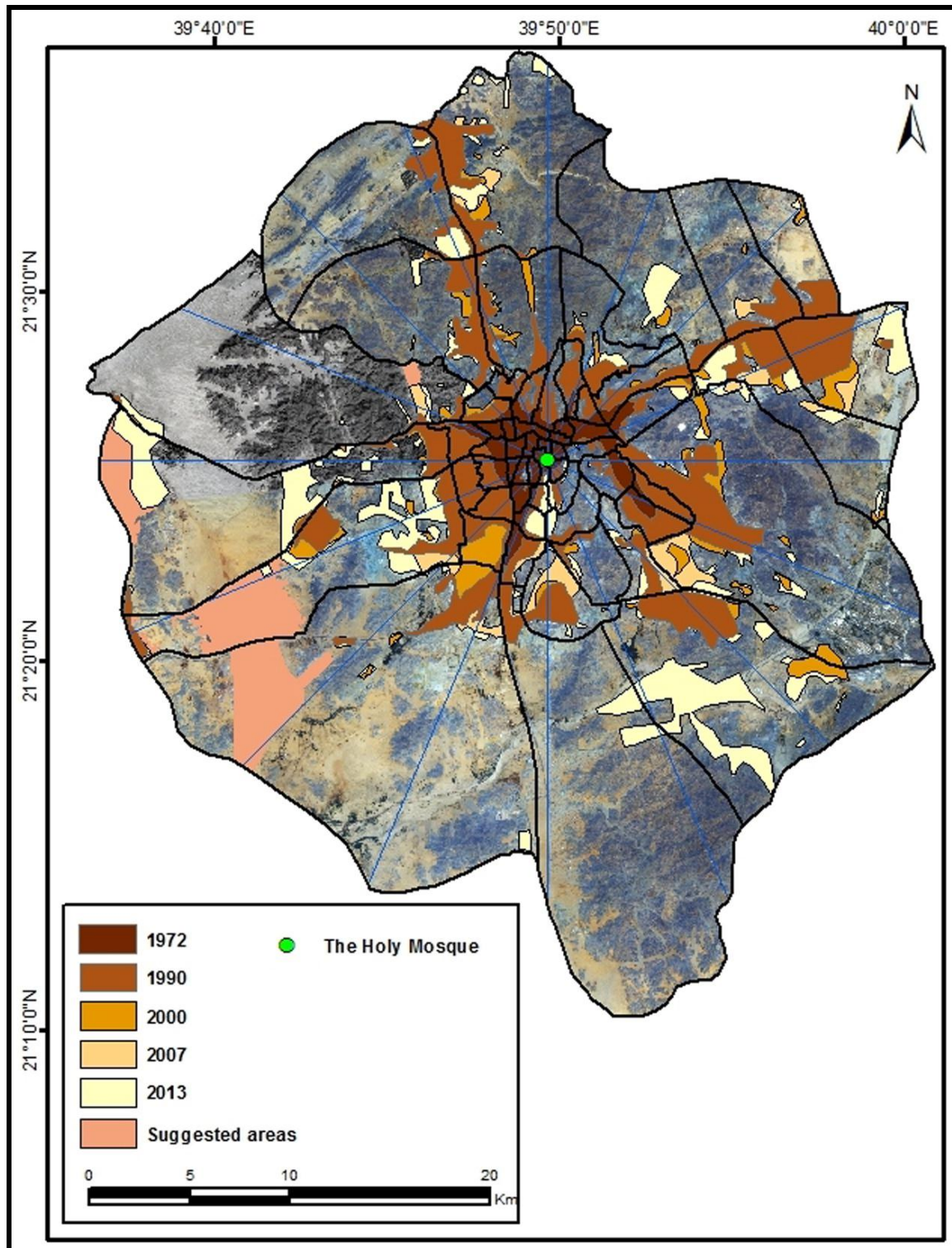

Figure 16. Suggested areas for urban expansion in Makkah: until 2035. 


\section{Conclusion}

Makkah city's population size was 366,509 , in 1974 , and continued to rise until it reached 1,534,731, in 2010. This rise was due to internal migration from rural and Bedouin areas, as well as international migrants who came to work in the city.

An unequal distribution of population across the region's cities was maintained in the top 22 most populated cities, from 1974 to 2010. Of these, only two cities (Jiddah and Makkah Al-Mukarramah) constituted threequarters of the total population of these major cities in 2010.

Makkah came in second place even with an increase in population size from $1,294,168$, in $2004-25.5 \%$ of the total population of the 22 cities in that year - to $1,534,731$, in $2010-25.2 \%$ of the total population of these cities in the same year-for a total increase of 240,563. The development projects primarily concentrated in Makkah Al-Mukarramah may have also caused the pattern of distribution to change in favor of this city.

Makkah included 60 districts, in 2010, of which eight districts occupied the top eight ranks for population size, in 2010. Al-Hindawiyyah came first with 5.3\%, followed by the following districts: Al-Jamiah, Al-Zahra, AlTaqwa, Al-Khalidiyyah, Al-Tandabawi, Ar Rashidiyyah, and Al-Andalus. The other districts each account for less than $3 \%$ of the city's total population in the same year.

Makkah's population growth rate decreased from 5.35\%, in 1974, to $2.99 \%$, in 2010 . The main reason for this initially higher population growth rate was the concentration of development projects in the city, which led to increased job opportunities and, consequently, increased immigration and migration from rural areas.

From 2004 to 2010, 34 districts recorded population growth rates higher than the city's general rate (2.94\%), including four districts occupying the top four slots during that period. More specifically, Al-Okaisheyyah experienced the largest population growth (4.89\%), followed by Al-Osailah, Al-Mashair, and Al-Malik Fahd with growth rates of, respectively, $4.71 \%, 4.45 \%$, and $4.04 \%$. An analysis of the number of years required for Makkah's population to double in size revealed that, in 23.8 years, the city's population will double.

The city has passed through four stages of urban growth since its inception until present time. The origination stage (until 1972) included urban sprawl that reached more than five kms from the core (the Holy Mosque) to the ESE and SSW. The first urban boom stage (1972-1990) included urban sprawl that reached more than $10 \mathrm{kms}$ in three directions (ENE, SE, and NNW). The retreat stage (1990-2007) involved urban sprawl 
that reached more than two kms in one direction (NNE). During the second urban boom stage (2007-2013), the growing urban sprawl reached more than $10 \mathrm{kms}$ in two directions (SSE and W).

The built-up area of Makkah in the origination stage (until 1972) was 25 $\mathrm{km}^{2}$, after which it grew to $281.14 \mathrm{~km}^{2}$, a figure representing the cumulative value of urban growth from the city's origin until 2013. Nearly half of the area added to the city's built-up area (46.3\% of the area in 2013) was developed during the first urban boom stage (1972-1990), while another large segment was added to the city's built-up area (31.3\% of the area in 2013) during the second urban boom stage (2007-2013).

The data on annual rates of additions to the city's built-up area emphasize that the city has the highest rate of added area during the second urban boom stage, which reached a top rate of $14.7 \mathrm{~km}^{2} /$ year. The average horizontal urban growth rate was recorded at its highest during the second urban boom stage (2007-2013), reaching 575 meters/year. The highest horizontal urban growth rates were found to the W, SW, and SE, and the city's future horizontal growth is expected to continue in those directions.

The built-up area doubled during the first urban boom stage to about five times the space, in 1972 (the base year). Then, during the retreat stage, the area doubled again to about seven time the area in the base year and doubled once again during the second urban boom stage, which was 10 times the area in the base year. The per capita built-up area decreased from $211.4 \mathrm{~m}^{2} /$ inhabitant, in 1990, until it reached a low of $169.9 \mathrm{~m}^{2} /$ inhabitants, in 2013.

Of the city's districts, 31 had a population, in 1990, of less than 10,000. This group shrank to 10, in 2013, due to on-going increases in the population size and the loss of districts to higher categories of population size. The number of districts with a population ranging from 30,000 to 50,000 experienced a continuous increase from only one district, in 1990-Al-Hindawiyyah (44,482 people) - to 17 districts, in 2013. Districts with a population ranging from 50,000 to 70,000 also steadily increased in number from when the city included only one such district, in 2000 - Al-Hindawiyyah with a population of 63.112 - to seven districts, in 2013: Al-Tandabawi, Al-Taqwa, Al-Khalidiyyah, Ar Rashidiyyah, Al-Andalus, Al-Zahra, and Al-Jamiah.

The number of districts with a built-up area of less than 500, 500-1,000, and 1,000-1,500 acres declined, while the number of districts with a built-up area of more than 2,000 acres increased. This was due to population movements from old to new districts at the edge of the city. 
Half of the city's districts, in 2013, had an urban density of less than 50 inhabitants/acre. Notably, their numbers decreased from 50 districts, in 1990, to 30 districts, in 2013, while the other half of the districts' urban density with more than 50 inhabitants/acre increased in number from 10 districts, in 1990, to 30 districts, in 2013, because of the city's continually growing population.

More than half of the city's districts, in 2013, had a per capita built-up area of less than $100 \mathrm{~m}^{2} /$ person. This number increased from 11 districts, in 1990, to 32 districts, in 2013. The rest of the districts' per capita built-up area was more than $100 \mathrm{~m}^{2} /$ person, but their numbers decreased from 49 districts, in 1990, to 28 districts, in 2013, because of the city's growing population.

The city's population is expected to reach 3,170,199 in 2035, according to the medium estimate calculated. Since the population was $1,534,731$ in 2010 , this projection represents an increase of 1,635,468 people. The urban space required to provide for this increase, according to the most likely scenario, is 62,812.5 acres to resettle 1,395,833 people, until 2035.

\section{Recommendations}

Based on these results, the city should reconsider the new planned areas already existing that occupy large areas of the city's urban space but provide a relatively small number of housing spaces within each planned area. This has caused the scattering of built-up areas in different directions in the city and has put greater demands on infrastructure and basic services, including sanitation, clean drinking water, electricity, and healthcare and educational facilities. Overall, this has created obstacles to the city's development.

Geographers must be given a role in the city's planning and development, including, in particular, population geographers. In addition, planners need to consider the nature of the strong relationship between the city's population and the area's holy sites, to plan successfully for the city's religious activities.

The authorities need to publish data on births and deaths at the city and district level, because of the vital importance of these data to analyses of population changes. Furthermore, the city needs to encourage vertical expansion in its urban growth to overcome its harsh topography and natural barriers such as mountains, rather than removing these or settled on them. The central business district's replanning needs to continue, clearing the old districts of slums and relegating the district's population gradually to the new planned districts, to allow a future expansion of the Holy Mosque. Finally, the development of approved new planned districts should continue but the adoption of any new plans for districts should stop because the city's urban reserve area is still quite large. 


\section{Appendices}

Appendix 1. Incremental growth in the built-up area through Makkah's developmental stages.

\begin{tabular}{|c|c|c|c|c|c|c|}
\hline Period & $\begin{array}{l}\text { until } \\
1972 \\
\end{array}$ & $\begin{array}{c}1972- \\
1990 \\
\end{array}$ & $\begin{array}{c}1990- \\
2000 \\
\end{array}$ & $\begin{array}{c}2000- \\
2007 \\
\end{array}$ & $\begin{array}{c}2007- \\
2013 \\
\end{array}$ & Total \\
\hline Direction & Meter & Meter & Meter & Meter & Meter & Meter \\
\hline $\mathrm{N}$ & 1,974 & 3,220 & 366 & 74 & 45 & 5,679 \\
\hline NNE & 3,746 & 998 & 1,967 & 87 & 80 & 6,878 \\
\hline $\mathrm{NE}$ & 3,742 & 1,382 & 49 & 1,356 & 10 & 6,539 \\
\hline ENE & 3,948 & 12,706 & 28 & 29 & 2,493 & 19,204 \\
\hline $\mathrm{E}$ & 3,837 & 4,602 & 450 & 126 & 0 & 9,015 \\
\hline ESE & 5,908 & 5,221 & 53 & 11 & 2,191 & 13,384 \\
\hline SE & 564 & 11,917 & 98 & 16 & 4,748 & 17,343 \\
\hline SSE & 541 & 3,680 & 59 & 20 & 10,643 & 14,943 \\
\hline S & 586 & 7,361 & 28 & 0 & 66 & 8,041 \\
\hline SSW & 5,790 & 2,843 & 42 & 614 & 56 & 9,345 \\
\hline SW & 2,564 & 4,077 & 32 & 602 & 6,940 & 14,215 \\
\hline WSW & 2,513 & 3,144 & 0 & 0 & 9,668 & 15,325 \\
\hline W & 2,766 & 3,315 & 174 & 0 & 14,553 & 20,808 \\
\hline WNW & 4,922 & 513 & 339 & 1,300 & 1,261 & 8,335 \\
\hline NW & 3,322 & 616 & 148 & 1,440 & 1,866 & 7,392 \\
\hline NNW & 3,914 & 12,662 & 0 & 0 & 583 & 17,159 \\
\hline Total & 50,637 & 78,257 & 3,833 & 5,675 & 55,203 & 193,605 \\
\hline
\end{tabular}

Source: Calculated by the author from satalite images of the city $(1972,1990,2007,2013)$. 


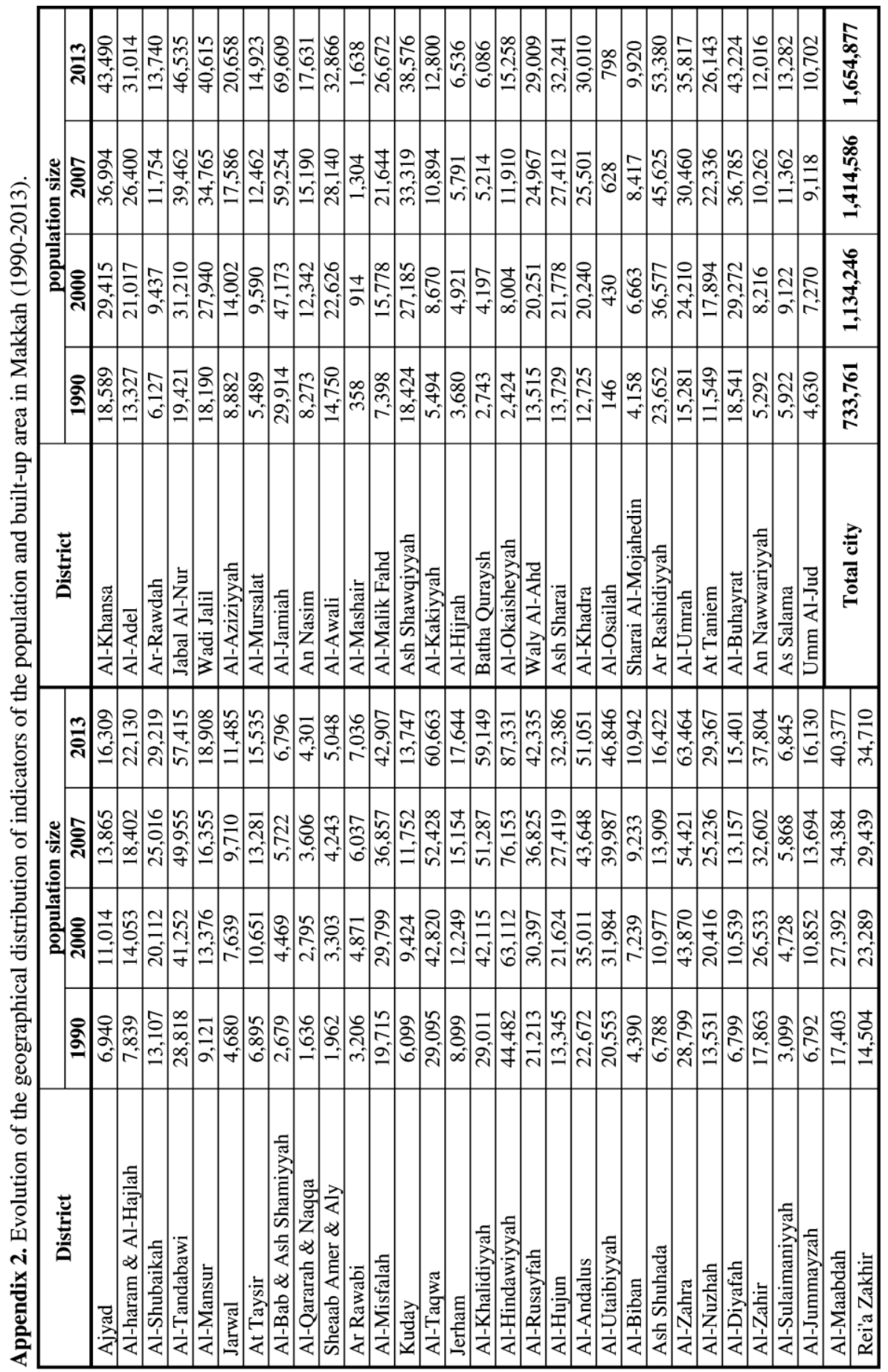




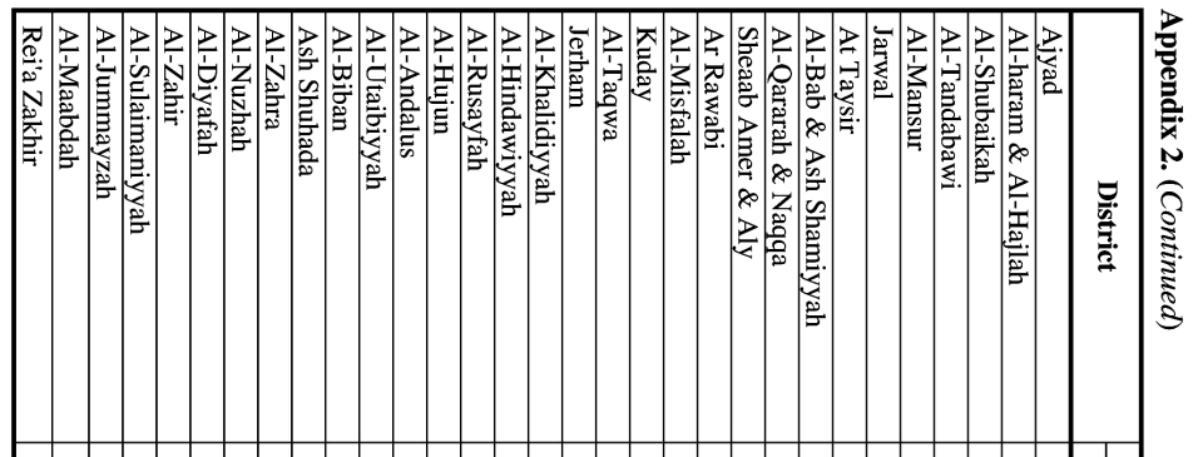

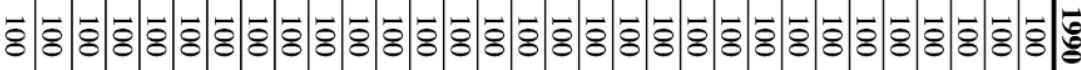

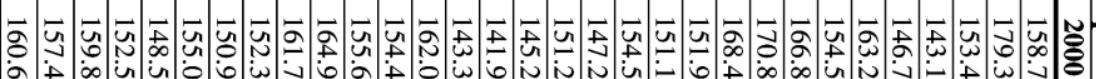

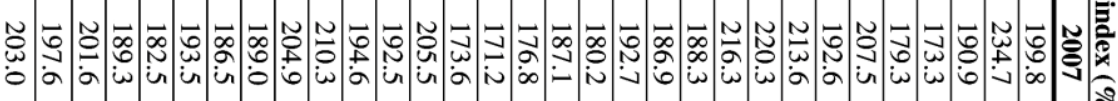

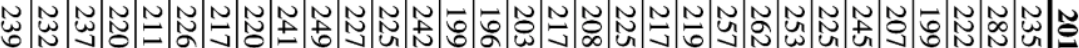

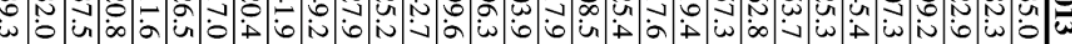

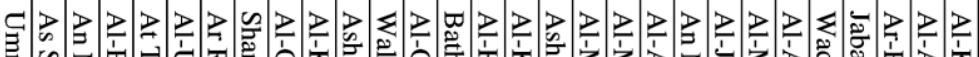
等

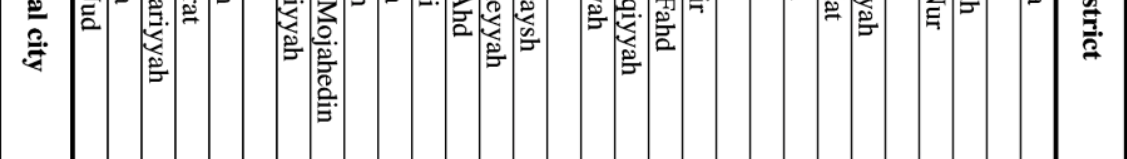

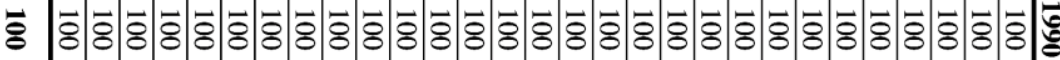

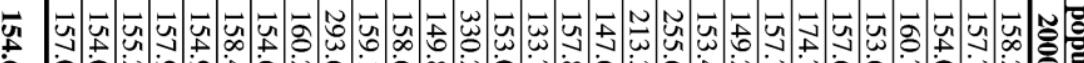

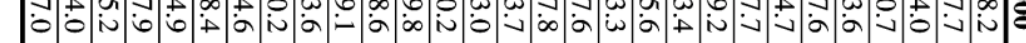

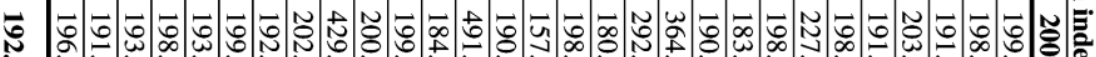

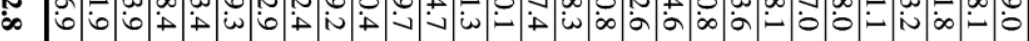

$N$ N

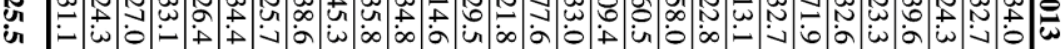




\begin{tabular}{|c|c|c|c|c|c|c|c|c|c|c|c|c|c|c|c|c|c|c|c|c|c|c|c|c|}
\hline సิ & 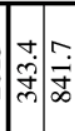 & & & & & & ?a & & & $\frac{3}{\infty}$ & 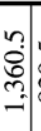 & & & & & $\mid \begin{array}{l}0 \\
0 \\
⿱ 亠 乂 \\
\alpha\end{array}$ & & 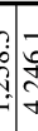 & & & & \begin{tabular}{l|l} 
\\
:
\end{tabular} & 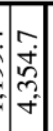 & 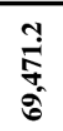 \\
\hline & 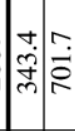 & : & $\begin{array}{l}\infty \\
\dot{2} \\
\infty \\
\infty\end{array}$ & & & & 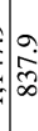 & & & 吕 & 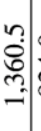 & & 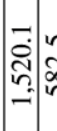 & & & $\mid \begin{array}{c}\infty \\
\dot{\infty} \\
\infty \\
\sim\end{array}$ & 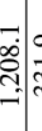 & & 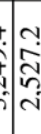 & \begin{tabular}{c}
1 \\
$\vdots$ \\
$\infty$ \\
\hdashline \\
$-\infty$
\end{tabular} & & & 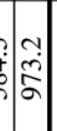 & 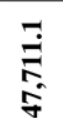 \\
\hline & $\stackrel{\vec{m}}{\vec{m}}=$ & & $\begin{array}{l}\infty \\
\infty \\
\infty \\
\infty\end{array}$ & & & & 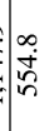 & $\stackrel{m}{\stackrel{m}{n}}$ & $\frac{\stackrel{+}{0}}{\stackrel{8}{8}}$ & 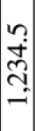 & : & & ஸू. & 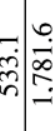 & $\begin{array}{l}n \\
\infty \\
\infty \\
0 \\
-\end{array}$ & $\begin{array}{l}\infty \\
\dot{\infty} \\
\infty \\
\curvearrowright \\
\curvearrowright\end{array}$ & (:) & & $\hat{i}$ & 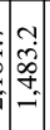 & . & 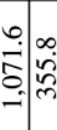 & فे & $\underset{\mathfrak{g}}{\mathfrak{g}}$ \\
\hline ఏ్ & 户े & : & $\begin{array}{l}0 \\
\partial \\
\dot{a} \\
\infty\end{array}$ & $\begin{array}{l}n \\
i \\
\text { ñ } \\
n\end{array}$ & & 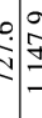 & 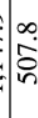 & 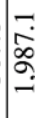 & $\begin{array}{l}n \\
0 \\
\text { co } \\
\text { mi }\end{array}$ & $\begin{array}{l}2 \\
2 \\
\\
=\end{array}$ & 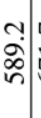 & & & & & $\begin{array}{l}\infty \\
\dot{\infty} \\
\infty \\
\sim\end{array}$ & & & & $\begin{array}{l}-1 \\
0 \\
0 \\
0 \\
-0\end{array}$ & & 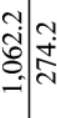 & 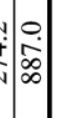 & 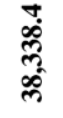 \\
\hline 密 & 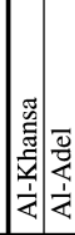 & 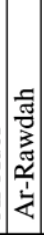 & 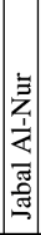 & 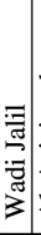 & & & 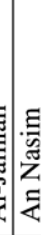 & & & 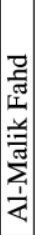 & 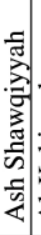 & 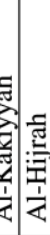 & 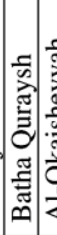 & & 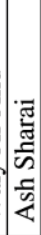 & 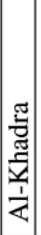 & & & & 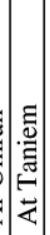 & & 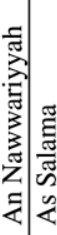 & : & 苞 \\
\hline लै & กี่ & กิ & & $\begin{array}{l}\text { : } \\
\dot{+} \\
\end{array}$ & $\dot{0}$ & 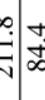 & $\infty$ & $\stackrel{\varrho}{g}$ & ڤેं & बें & ले & & & & กิ่ & $\begin{array}{l}0 \\
i \\
i \\
i n\end{array}$ & & & & \begin{tabular}{l}
0 \\
$\dot{\infty}$ \\
$\infty$ \\
\hdashline
\end{tabular} & & & $\stackrel{m}{2}$ & 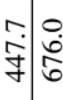 \\
\hline تِ & 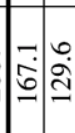 & 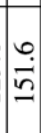 & $\hat{\dot{q}}$ & $\begin{array}{l}0 \\
\dot{0} \\
\end{array}$ & : & 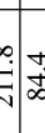 & 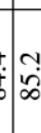 & 等 & ले & $\begin{array}{l}0 \\
0 \\
0 \\
0 \\
0\end{array}$ & $\mid \begin{array}{l}0 \\
\dot{0} \\
\dot{N} \\
0\end{array}$ & 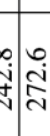 & & & กิ่ & $\begin{array}{l}0 \\
\text { i } \\
\\
\text {. }\end{array}$ & & & $\stackrel{n}{n}$ & \begin{tabular}{l}
0 \\
$\dot{\infty}$ \\
\hdashline \\
\hdashline
\end{tabular} & & & 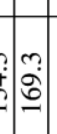 & 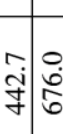 \\
\hline ప్రి & 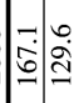 & $\bar{n}$ & ga & $\begin{array}{l}0 \\
\dot{0} \\
\dot{g}\end{array}$ & 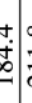 & 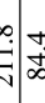 & $\stackrel{\sim}{\sim}$ & 等 & $\stackrel{?}{=}$ & 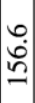 & ડ্ণি & 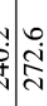 & $=\left(\begin{array}{l}\infty \\
\vdots \\
z\end{array}\right.$ & 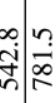 & ฟิ & $\begin{array}{l}0 \\
\text { i. } \\
\text { n. } \\
\end{array}$ & : & & & 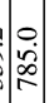 & & & 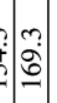 & \begin{tabular}{c|c}
$\hat{i}$ & 0 \\
$\dot{y}$ & $\stackrel{0}{b}$
\end{tabular} \\
\hline ఏ్ & : & 节 & 字 & $\begin{array}{l}0 \\
\dot{+} \\
\end{array}$ & 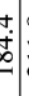 & $\begin{array}{l}\infty \\
\end{array} \mid$ & $\infty$ & 䟢 & $\stackrel{n}{n}$ & 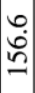 & ડ্ণ & \begin{tabular}{lll}
$\qquad$ \\
\hdashline \\
\cline { 1 - 1 }
\end{tabular} & 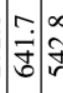 & $\begin{array}{lll}\infty \\
\\
\end{array}$ & ฟิ & $\begin{array}{l}0 \\
\dot{0} \\
n \\
n\end{array}$ & 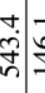 & $\begin{array}{lll}0 \\
\dot{b}\end{array}$ & : & \begin{tabular}{l}
0 \\
$\dot{a}$ \\
0 \\
\hdashline \\
$⿱ 乛$
\end{tabular} & & & 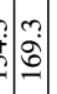 & $\begin{array}{c}\hat{j} \\
\text { j }\end{array}$ \\
\hline & 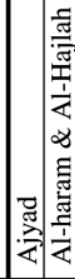 & 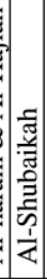 & 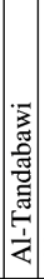 & 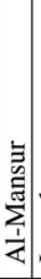 & & 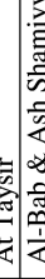 & 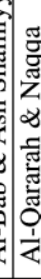 & 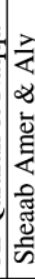 & 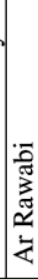 & 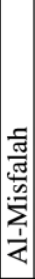 & 㞼: & 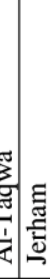 & 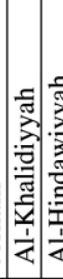 & 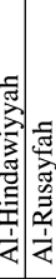 & 变 & & 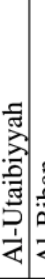 & 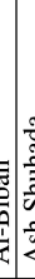 & & 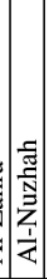 & : & 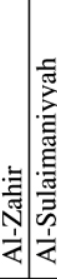 & : & 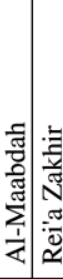 \\
\hline
\end{tabular}




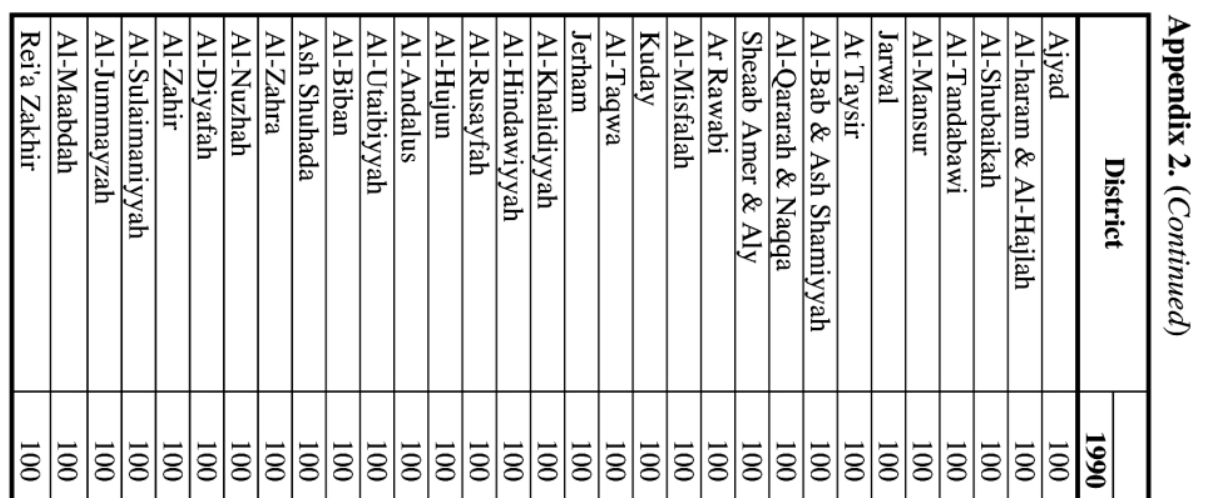

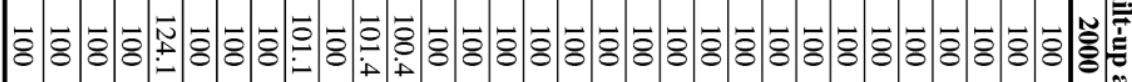

Бे

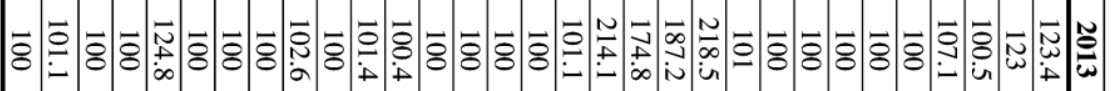

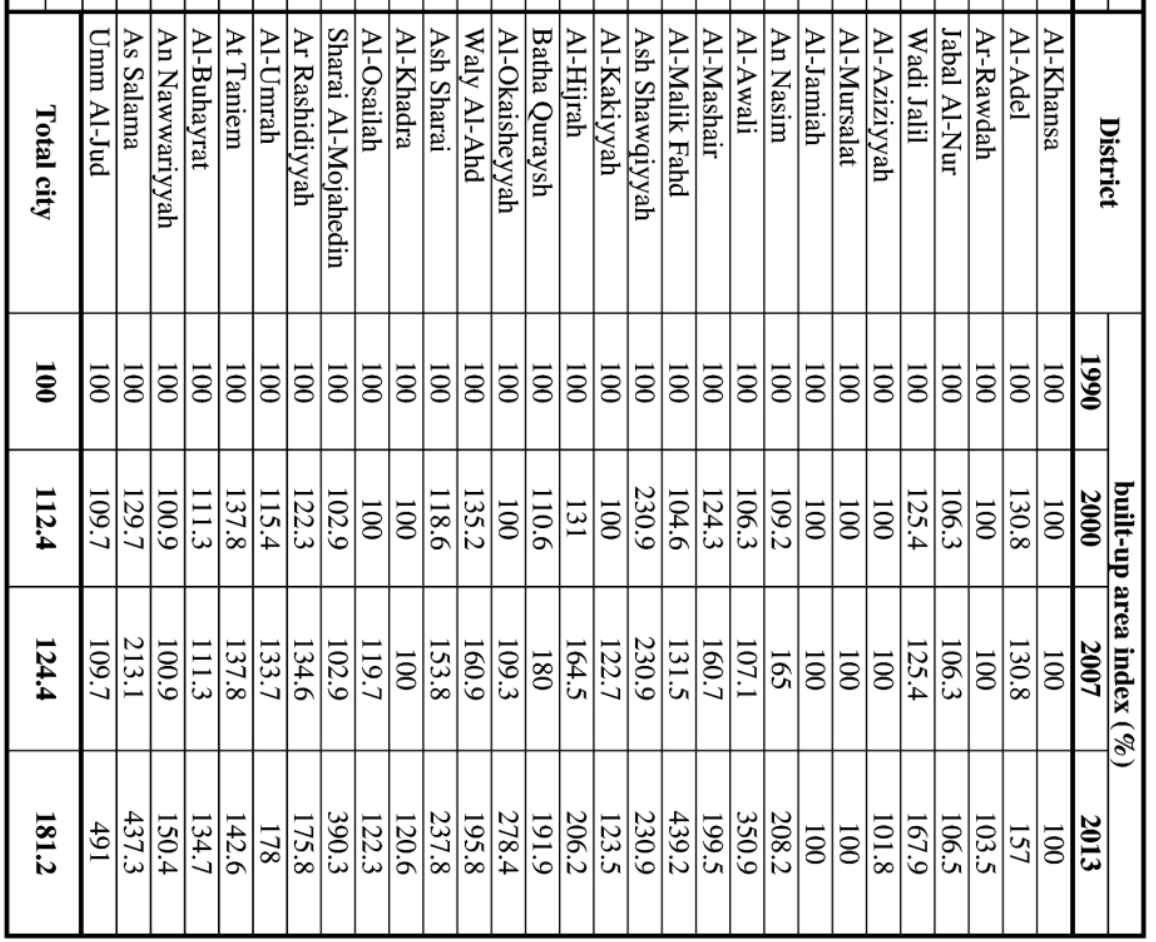




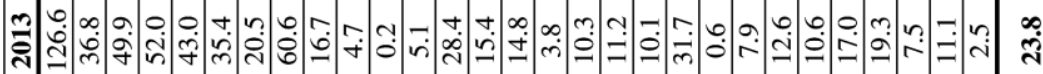

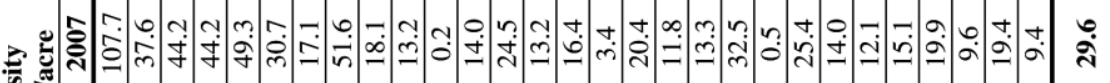

竞

菅

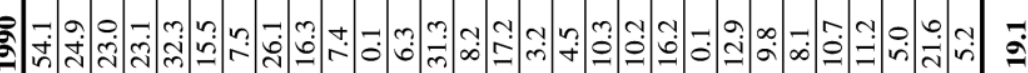

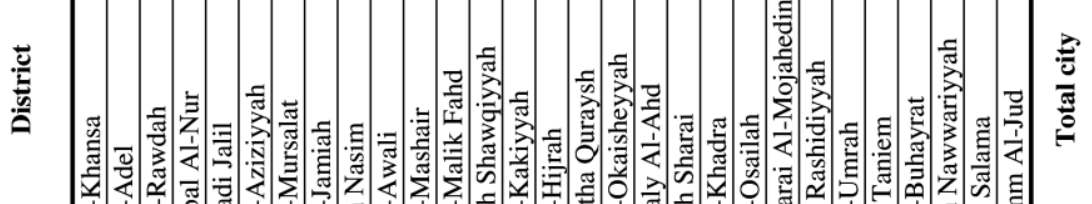

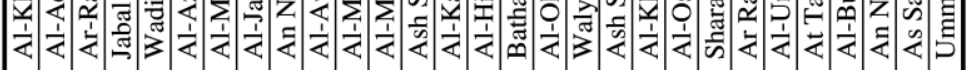

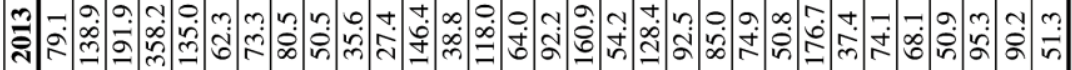

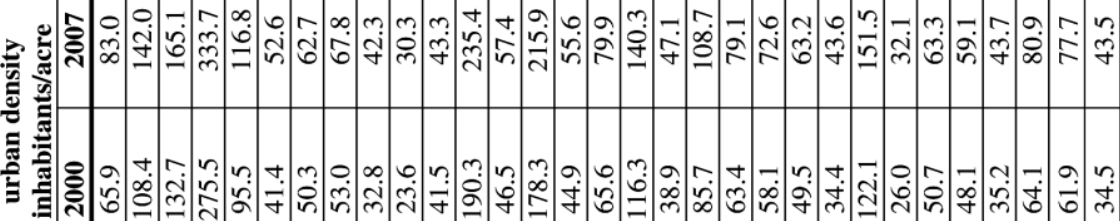

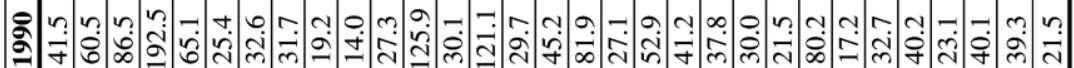

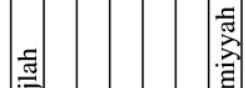

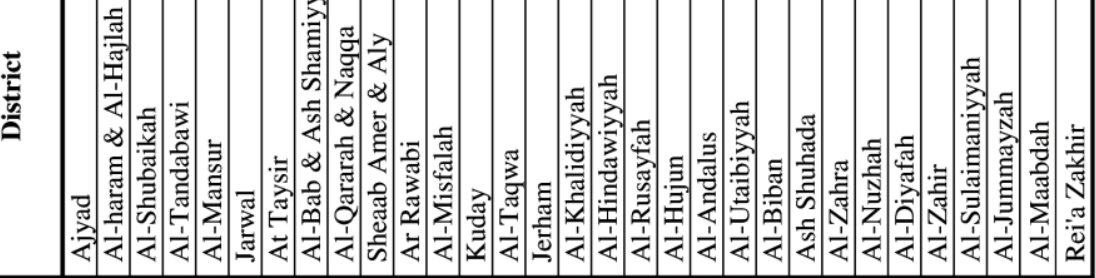




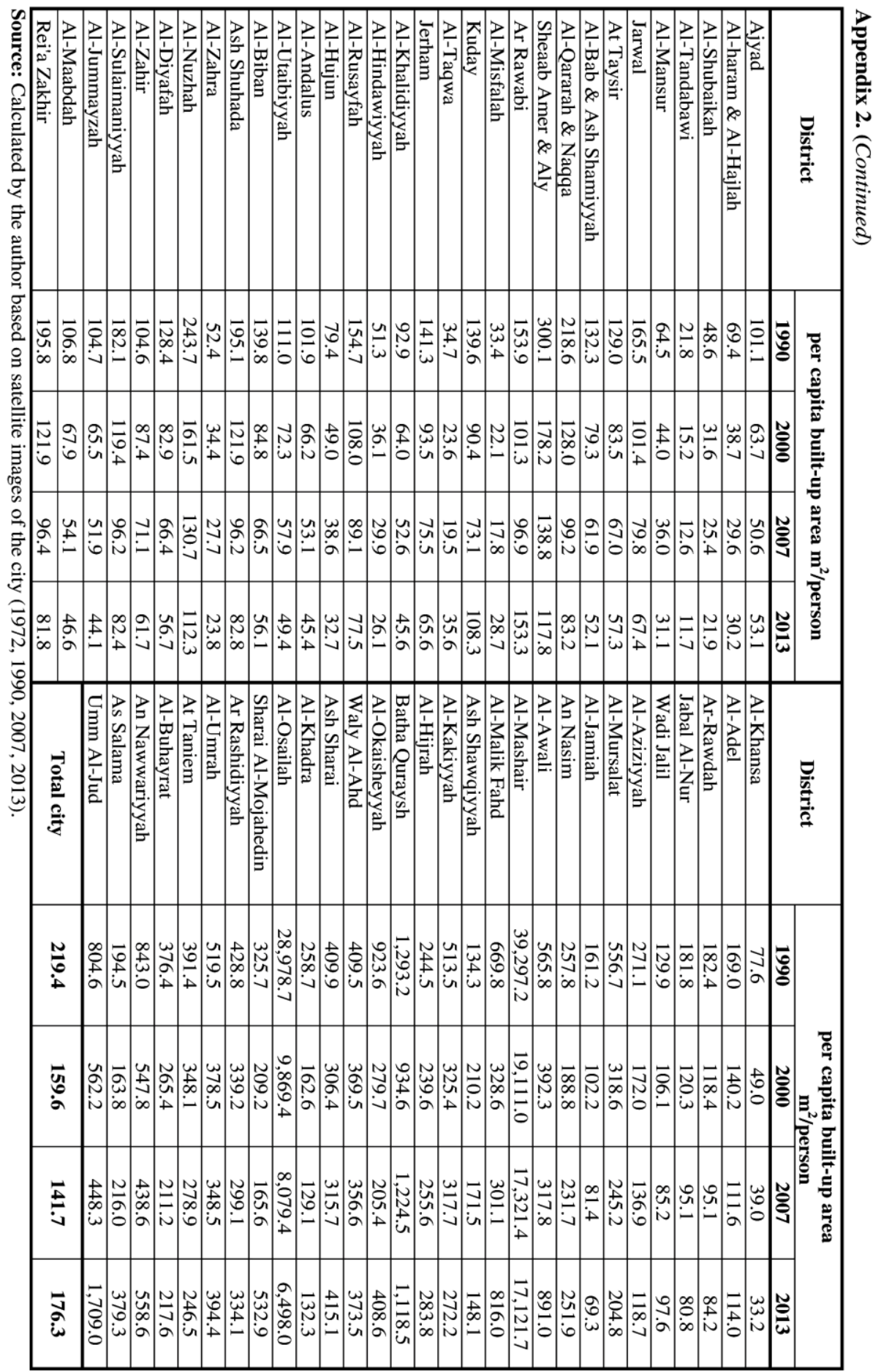




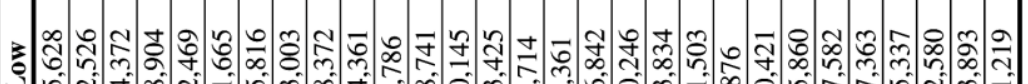
ปी

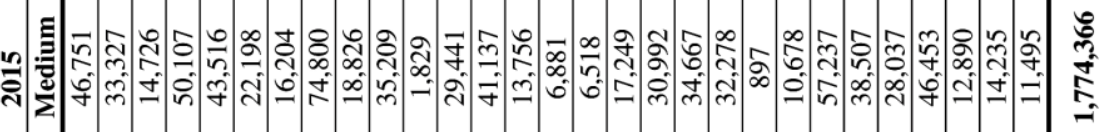

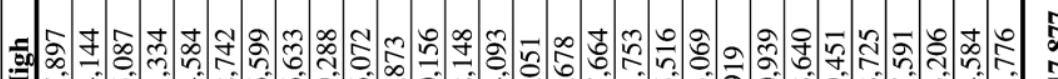

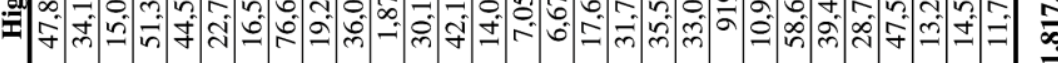

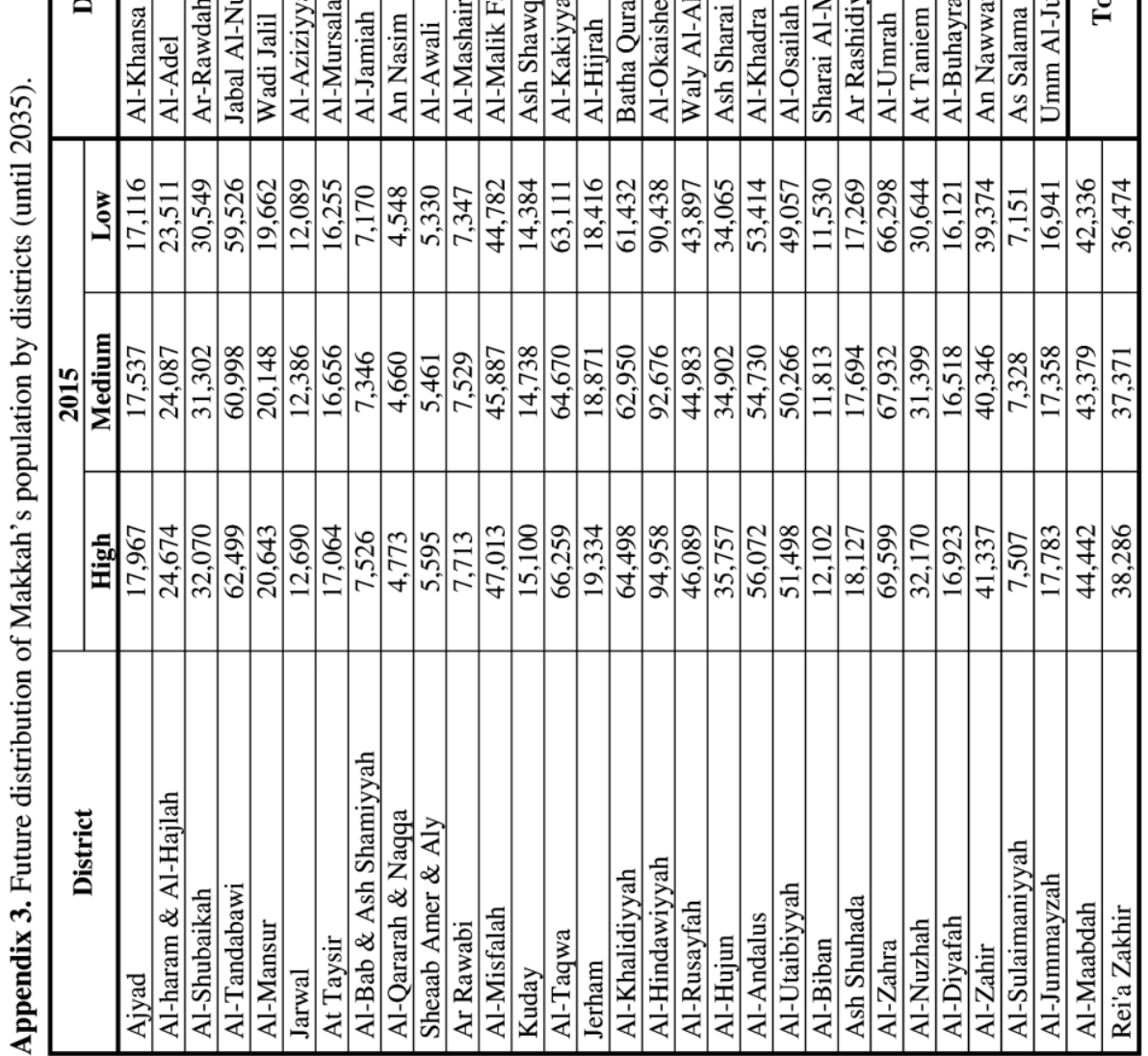

事 


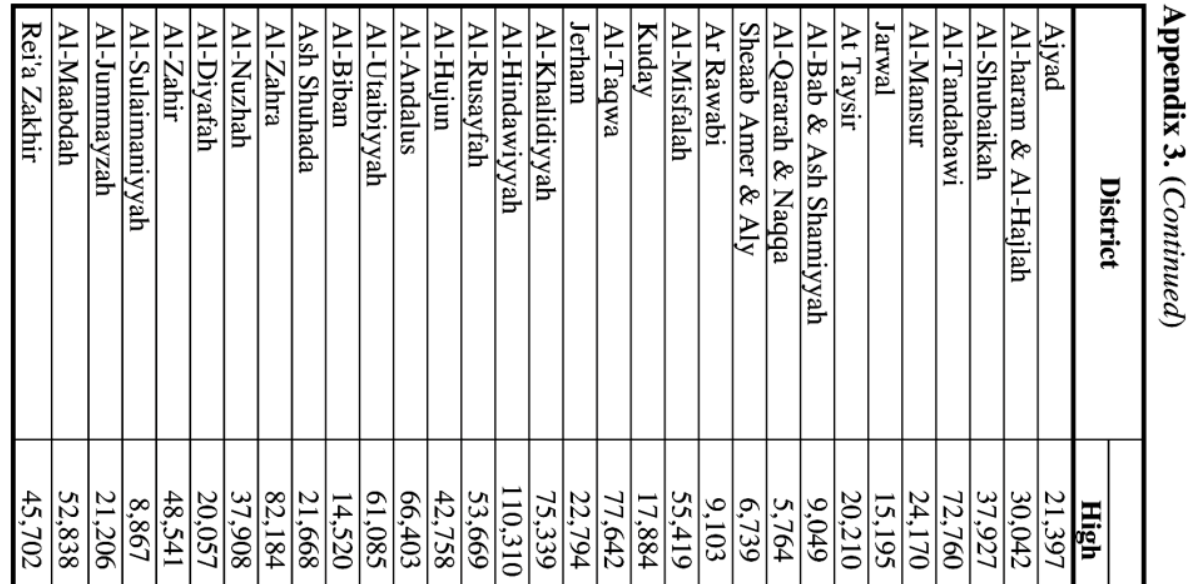

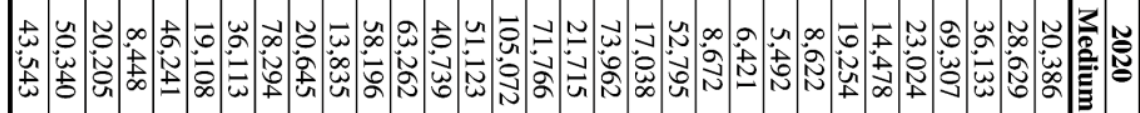

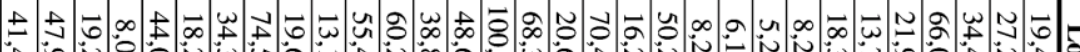

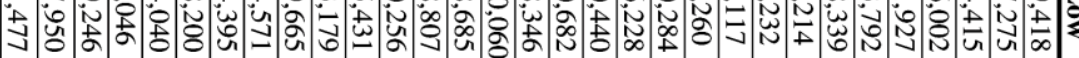

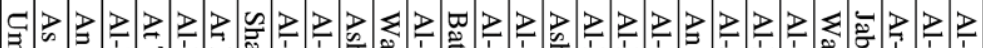

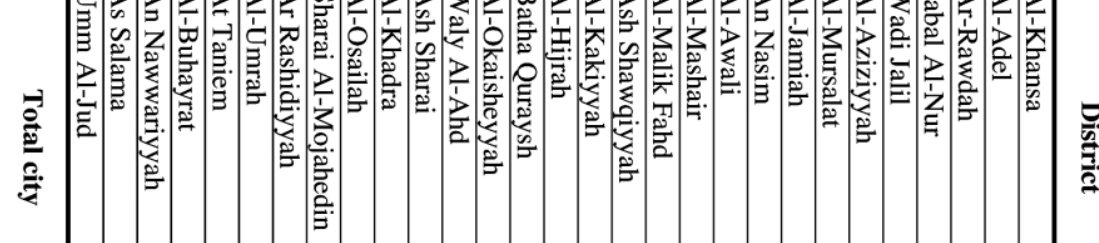

ص 芯

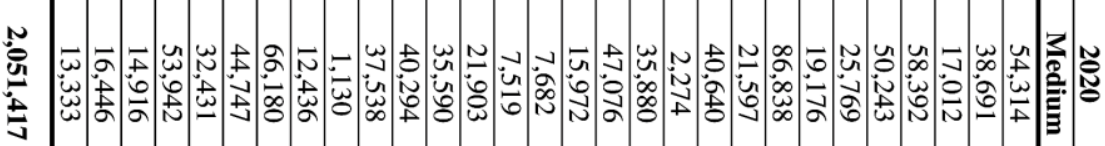
茎 至 


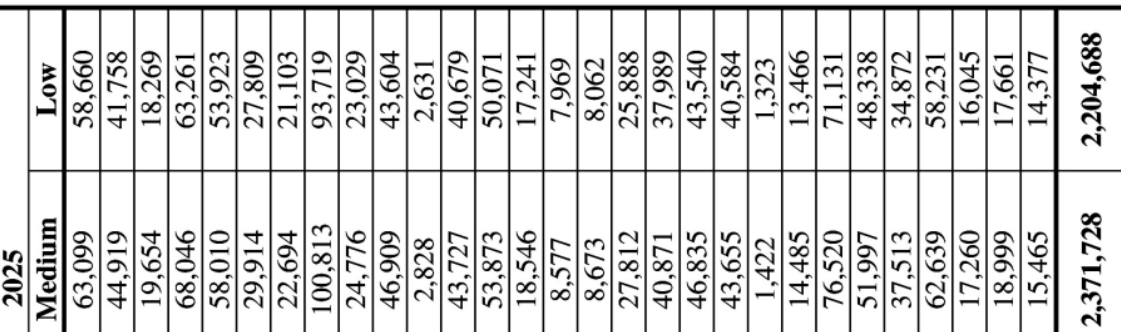

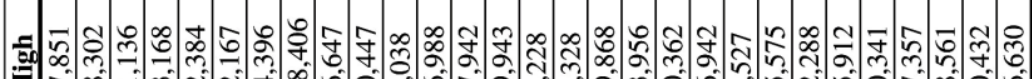

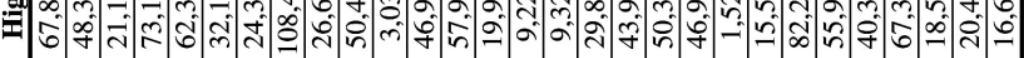

\section{ํำ}

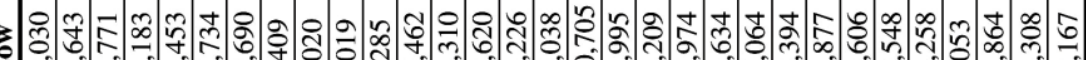

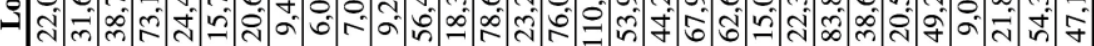

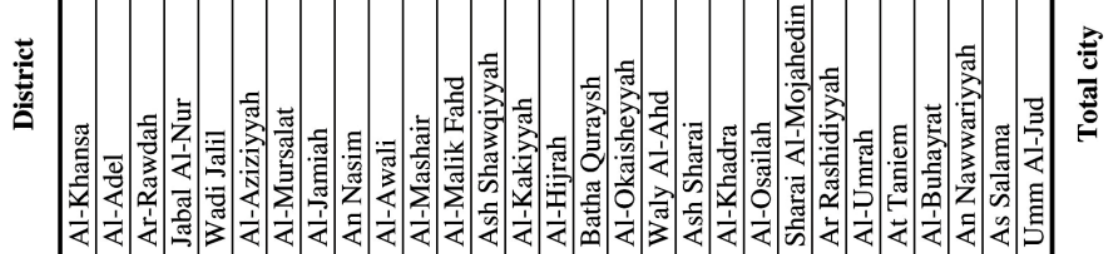

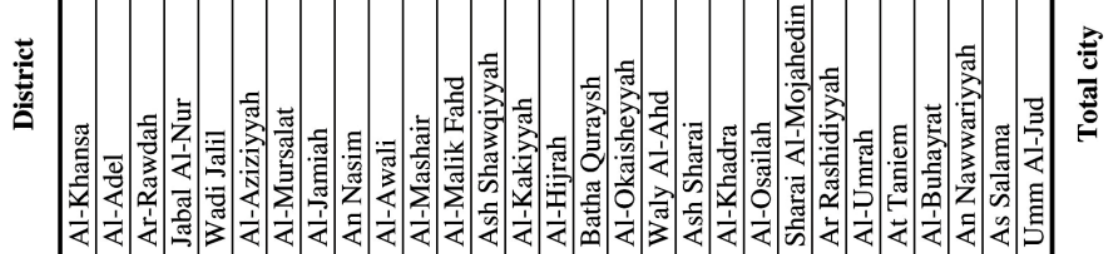

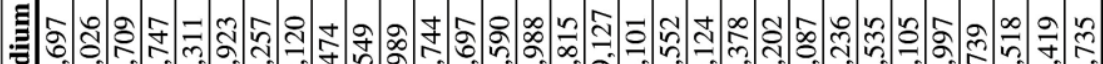

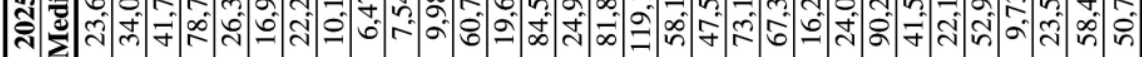

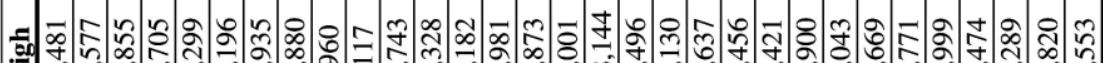

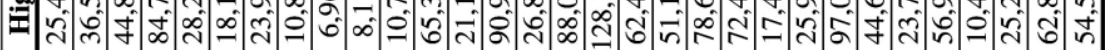

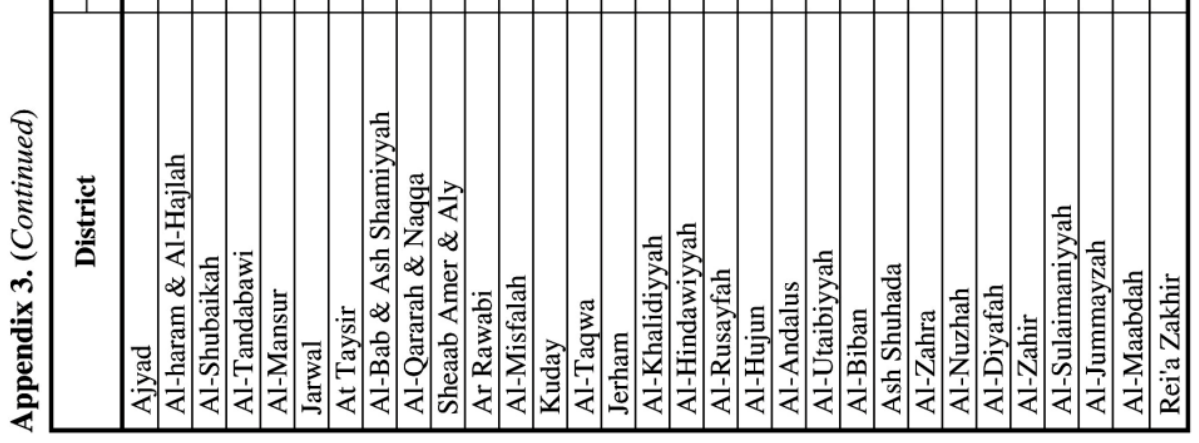




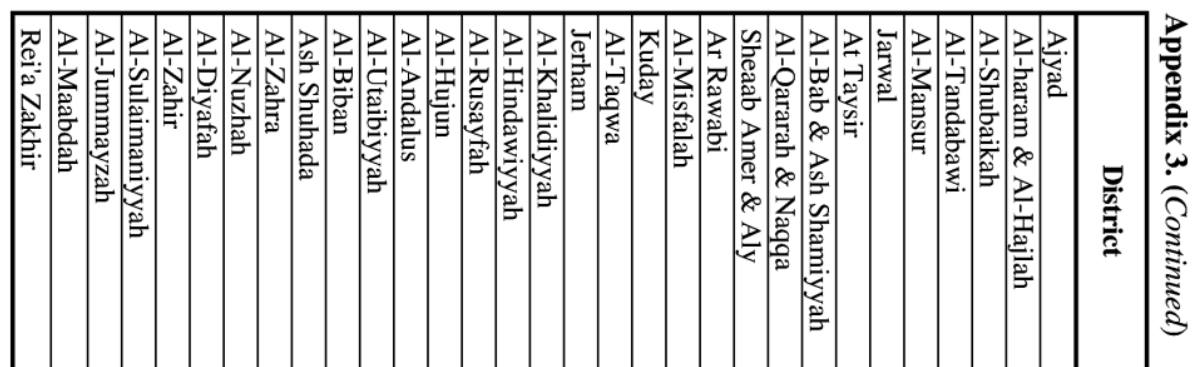

N.

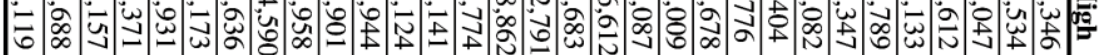

Uి 声

U

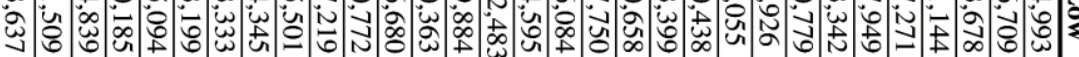

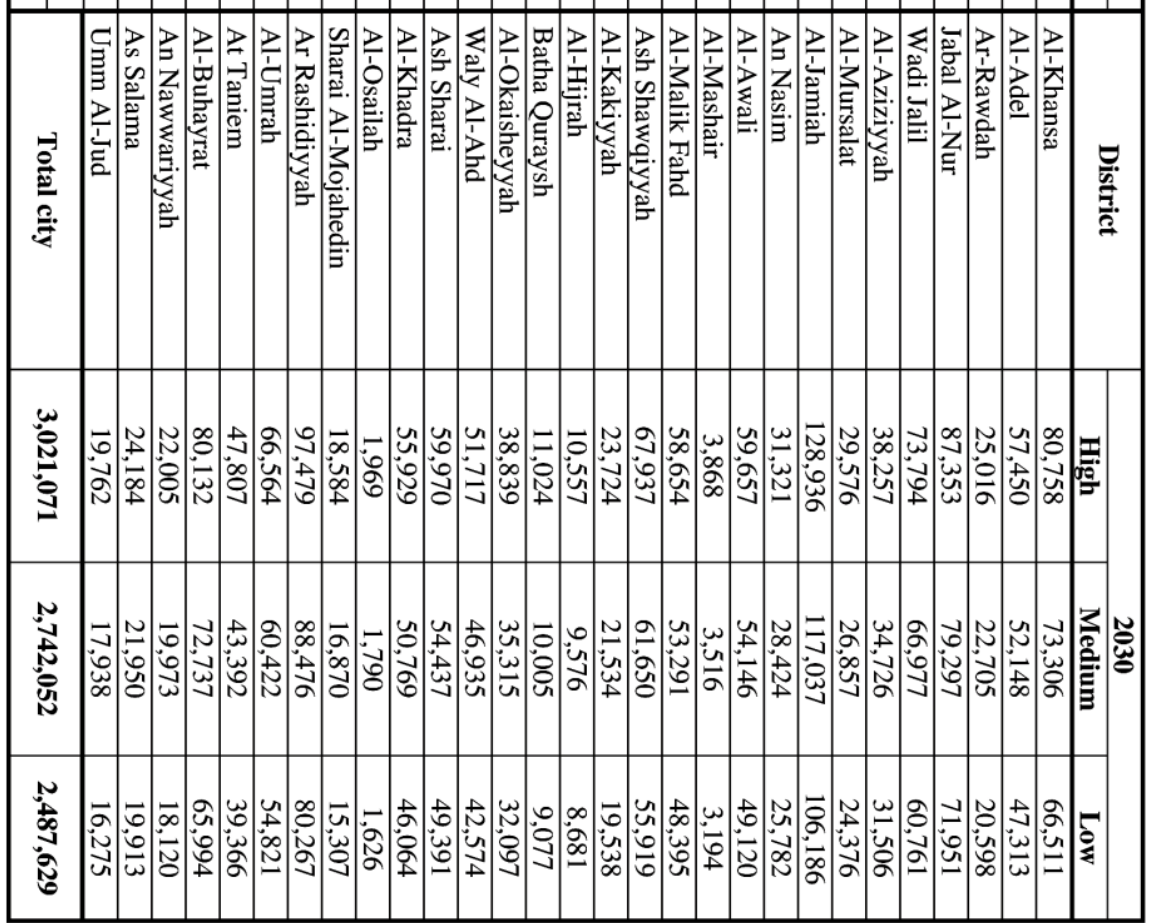




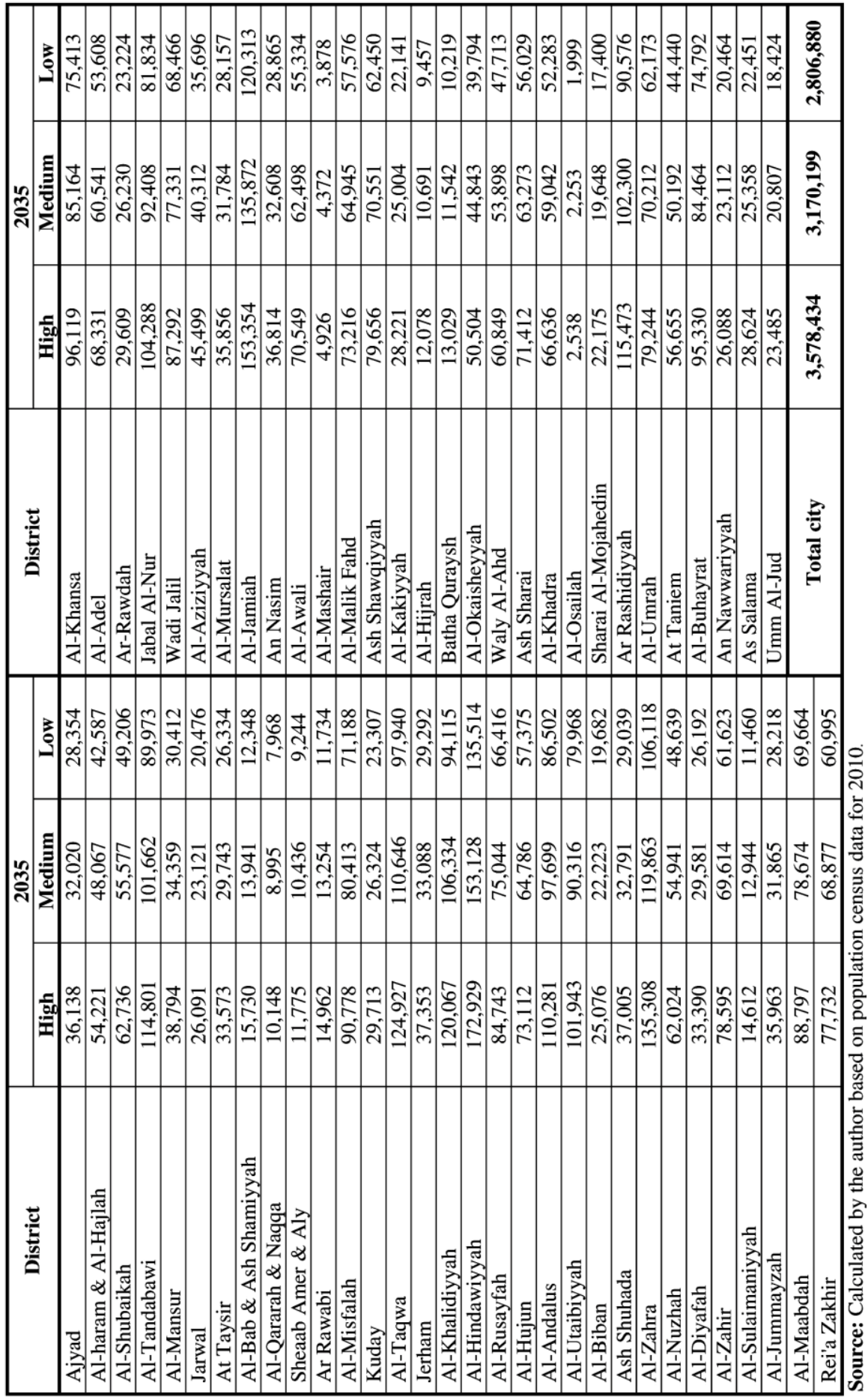




\section{References}

1. Al-Gabbani, M. (1999). Spatial distribution of population and development in Saudi Arabia 1974-1992. research papers in geography, occasional papers, No. 37, the Saudi geographical society, King Saud university, Riyadh, K.S.A. (in arabic)

2. Al-Hajri, F. (2002). Planning and development of the manpower in the Kingdom of Saudi Arabia: geographic study. faculty of arts journal, Menoufia university, Egypt.(in Arabic)

3. Al-Jabri, N. (2008). Geography of settlement centers in the administrative region of makkah Al- Mukarramah. Makkah, K.S.A. (in Arabic)

4. Al-Saleh, N. (1991). Primary schools for males in Makkah: A Study in the characteristics of distribution and its patterns. In the scientific book of the fourth geographical symposium on geography departments in K.S.A., 2426/12/1991, Vol. 2, department of geography-college of social sciences, Umm Al-Qura university, Makkah, K.S.A. (in Arabic)

5. Al-Seryane, M. (1986). Makkah Al-Mukarramah: A study in population change 1974-1983. publications of cultural Makkah club, K.S.A. (in Arabic)

6. Al-Seryane, M. (1991). Features of urbanization in Saudi Arabia. Research series of social sciences, institute of scientific researches, Umm Al-Qura university, No. 16, Makkah, K.S.A. (in Arabic)

7. Al-Thomaley, M. (1988). Recruitment of workers in the private sector in Saudi Arabia: A theoretical study of some economic indicators. research series of social sciences, institute of scientific researches, Umm Al-Qura university, No. 6, Makkah, K.S.A. (in Arabic)

8. Clarke, J. (1972). Population geography. 2nd edition, pergamon press, England.

9. Meselhy, F. (2009). Geography of settlement. Cairo, Egypt. (in Arabic)

10. Rowland, D. (2003). Demographic methods and concepts. Oxford university press, New York.

11. Siegel, J. \& Swanson, D. (2004). The methods and materials of demography. 2nd edition, Elsevier academic press, U.S.A.

12. United Nations. (2001). World Population Monitoring 2001: Population, environment and development. New York.

13. United Nations. (2008). World Population Policies 2007. population division, department of economic and social affairs, New York.

14. United Nations. (2010). World Population Policies 2009. population division, department of economic and social affairs, New York.

15. United Nations. (2011). International Migration Report 2009: A Global Assessment. population division, department of economic and social affairs, New York.

16. United Nations. (2013). World Population Policies 2011. population division, department of economic and social affairs, New York.

17. United Nations. (2013). World Population Policies 2013. population division, department of economic and social affairs, New York.

18. United Nations. (2014). World Urbanization Prospects: The 2014 Revision, Highlights. population division, department of economic and social affairs, New York.

19. Woods, R. (1979). Population analysis in geography. Longman, New York. 